\title{
Can we have a distinctive theory of memory?
}

\author{
STEPHEN R. SCHMIDT \\ Middle Tennessee State University, Murfreesboro, Tennessee
}

\begin{abstract}
The current status of the concept of distinctiveness as applied to memory research is discussed. In spite of the fact that distinctiveness is difficult to define, an increasing number of memory phenomena have been explained in terms of distinctiveness. These phenomena are grouped into four classes, which vary in how distinctiveness is operationalized. Distinctiveness has different effects on memory performance, depending on how it is defined, suggesting that the concept of distinctiveness has been overapplied. In addition, current theoretical explanations of the effects of distinctiveness on memory fail to specify what the different definitions of distinctiveness have in common, and fail to encompass adequately the broad range of phenomena to be explained. A limited theory of distinctiveness is proposed, in order to explain why conceptually incongruent material is remembered well.
\end{abstract}

The unusual, bizarre, or distinctive event seems inherently more memorable than common, everyday occurrences. Psychologists often refer to this phenomenon as the von Restorff (1933) effect. The effects of distinctiveness on memory are exploited in textbooks in which major concepts are printed in bold print, and in virtually every form of advertising in which loud music, bright colors, or other distinctive stimuli scream for our attention. Recently, memory researchers have invoked the concept of distinctiveness to explain an increasing range of phenomena, from detailed memory of the space shuttle explosion (McCloskey, Wible, \& Cohen 1988) to enhanced memory of concrete words (Marschark, Richman, Yuille, \& Hunt, 1987). Unfortunately, the features shared by the many faces of distinctiveness have not been specified, and the mechanisms responsible for the effects of distinctiveness on memory have not been delineated.

The current status of research concerning the effects of distinctiveness on memory is reviewed below. For the sake of brevity, this review will be restricted to a discussion of long-term memory performance. Many of the issues that will be raised, however, could easily be applied to research concerning short-term memory performance as well. A brief historical review of distinctiveness in memory research will be followed by an analysis of the definition of distinctiveness. Several criteria will be selected that should enable us to classify previous operational definitions of distinctiveness. The different classes of distinctiveness do not lead to a common set or pattern of results, and thus they do not converge on a common hypothetical construct. Prominent theoretical frameworks will be considered, but none of the theories encompasses the many faces of distinctiveness. A more limited definition of distinctiveness will be proposed, and a theoretical framework

Special thanks to Constance R. Schmidt, Mark A. McDaniel, and F. I. M. Craik for comments on earlier versions of the manuscript. Requests for reprints should be sent to Stephen R. Schmidt, Department of Psychology, Middle Tennessee State University, Murfreesboro, TN 37132. for the effects of distinctiveness, based on this limited definition, will be presented.

\section{HISTORICAL ANTECEDENTS}

The distinctiveness hypothesis is a direct descendent of the von Restorff effect, which was investigated extensively in the 1950 s and $60 \mathrm{~s}$. In the most recent review of this research, Wallace (1965) discussed three ways in which the von Restorff effect was studied. In the first, the experimenter performs some physical operation on the item so that it is unique in a given context. For example, the item may be printed in red, while the rest of the list is printed in black. Memory for this item is superior to memory for the same item printed in black in a list of items printed in black. A second type of manipulation occurs when an item of one conceptual type is inserted in a homogeneous list of items of another conceptual type. For example, a three-letter word may be embedded in a list of CVCs (Jenkins \& Postman, 1948). A third type of isolation is created when an item of one type is embedded in a series of items of another type, with both types of items equally represented in the entire list.

In these early investigations of distinctiveness, good memory for distinctive events was viewed as an empirical phenomenon to be explained in terms of the theory of the day. For example, Rundus (1971) tested a rehearsal explanation of the von Restorff effect within the context of the Atkinson and Shiffrin (1968) model. Schmidt (1985) contrasted encoding and retrieval models of conceptual distinctiveness. More recent treatments of distinctiveness have shifted toward the use of distinctiveness itself as an explanation of good memory. For example, Eysenck (1979) recast the levels of processing framework into a theory based on distinctiveness. Semantic encoding tasks were thought to produce a more unique or distinctive memory trace than were phonetic or structural tasks. Distinctive encodings aided discrimination processes important for good recognition performance. 
Distinctiveness as a theory of memory was further developed by Hunt and his associates (Hunt $\&$ Einstein, 1981; Hunt \& Elliot, 1980; Hunt \& Mitchell, 1978, 1982) to explain enhanced memory for orthographically unusual words. According to Hunt's "distinctiveness hypothesis," distinctive events lead to the storage of individual-item information that serves to delineate the distinctive items from other items in a search set.

In more recent developments, the concept of distinctiveness has been further extended. McDaniel and Einstein (1986) invoked the concept of distinctiveness to explain the effects of bizarre imagery on memory. Marschark et al. (1987) reexamined the effects of word concreteness on memory by focusing on the greater distinctiveness of concrete information relative to abstract information. McCloskey et al. (1988) argued that memory for emotionally traumatic events (flashbulb memories) could be explained in terms of distinctiveness. Several researchers have tried to explain the generation effect in terms of distinctiveness (Begg, Snider, Foley, \& Goddard, 1989; Kinoshita, 1989; Schmidt, 1988, 1991). Graf and Ryan (1990) have argued that only distinctive encoding tasks produce "format-specific" effects on tests of implicit and explicit memory. Pezdek, Whetstone, Reynolds, Askari, and Dougherty (1989) have contrasted the "von Restorff interpretation" with "retrieval advantage" and "encoding differences" interpretations of the consistency effect. Apparently the concept of distinctiveness has evolved from an empirical phenomenon to be explained to an explanation of memory phenomena. However, such explanations appear to be circular, in that good memory performance is used as an index of distinctiveness, and distinctiveness is invoked to explain good memory performance.

\section{WHAT IS DISTINCTIVE?}

To avoid circular explanations of memory, an adequate definition of distinctiveness is needed. Distinctiveness is generally defined in terms of shared features in memory (Eysenck, 1979; Nelson, 1979). Events are distinctive if the stored representation of the event shares few features with other items in memory. By this definition, distinctiveness is simply the converse of similarity. Tversky (1977) defined the similarity between concepts in terms of a linear combination of common and distinctive (i.e., unshared) features. The concepts school and house share a number of features, including man-made structures, having a roof, having walls, and so forth, and thus they are similar. In the context of a list of other man-made structures, whale would be a distinctive word because a whale does not share these features.

However, Murphy and Medin (1985) have argued that the feature overlap approach to conceptual relations is inadequate. Shared features cannot be used to define conceptual relations, because the set of potential features is too large and the weight to be given to specific features is context-bound. Instead of a feature overlap definition of similarity or distinctiveness, Murphy and Medin sug- gest that the relations between concepts be defined in terms of mental theories or structures. Concepts such as house and school belong to the same conceptual category only when they fit into a coherent conceptual theory about the world. Thus we consider a "whale" a type of "mammal," even though, in terms of similarities of perceptual features, whales are more similar to "fish" than to common "mammals." The reason why we may classify whales as mammals is that we have accepted modern theory regarding the evolution of biological structures. However, in the context of a list of animals such as cat, dog, whale, and shark, whale and shark may be conceptually grouped because they are animals of the sea. Thus, "similarity [and distinctiveness] is in the eyes-and the theories-of the beholder' (Murphy \& Medin, 1985, p. 305), and it is influenced by such factors as expertise, culture, and context.

Unfortunately, defining similarity and distinctiveness in terms of mental theories does not provide an adequate index of distinctiveness. Conceptual frameworks are context-bound; they vary across individuals; and they are difficult or impossible to measure. Murphy and Medin (1985) suggested that conceptual coherence can be determined by how easy a concept is to learn. A good conceptual group will conform to a coherent theory and will be easily comprehended by the learner. Conversely, distinctiveness could be determined by the difficulty that subjects have in comprehending and learning material. We are forced to reject this approach to a definition of distinctiveness because: (1) it leaves us defining similarity and distinctiveness in terms of the performance measures that we wish to predict from similarity and distinctiveness; and (2) it invokes a paradox in which similarity is indexed in terms of ease of recall, whereas its converse (i.e., distinctiveness) is also thought to produce superior recall.

A third approach to defining distinctiveness is based on the physiological responses to distinctive stimuli. Sokolov (1963) distinguished between two types of responses: orienting and defensive responses. The orienting response, which is elicited by novel stimuli, involves heart-rate deceleration, increased skin conductance, peripheral vasoconstriction, pupillary dilation, a feeling of pleasantness, and positive feedback to the reticular activating system (Isen, 1984). These responses are indicative of increased attention to the stimuli. In contrast, the defensive response is elicited by sudden or intense stimuli and involves heartrate acceleration, peripheral vasoconstriction, pupillary constriction, increased skin conductance, a feeling of unpleasantness, and negative feedback to the reticular activating system (Isen, 1984). These responses are indicative of a blocking of external stimuli.

A direct link between distinctiveness and orientation has been established by recent research. Gati and Ben-Shakhar (1990) have argued that two factors are important in eliciting the orienting response: novelty and significance. In this approach, the novelty of a stimulus is based on the degree of feature overlap between the stimulus and preceding stimuli. Because distinctiveness can also be defined 
in terms of feature overlap, distinctive stimuli should generally lead to an orienting response. However, significance also leads to orientation. The significance of the stimulus is determined by the degree of feature overlap between the stimulus and a significant stimulus. The magnitude of the orienting response is determined by the additive effects of novelty and significance (Gati \& BenShakhar, 1990).

In addition to considering whether a stimulus leads to an orienting response or a defensive response, one must also consider whether a stimulus leads to cortical or visceral arousal (Isen, 1984). Several researchers have measured the magnitude of cortical responses in von Restorff experiments (Karis, Fabiani, \& Donchin, 1984; Neville, Kutas, Chesney, \& Schmidt, 1986). For example, Karis et al. (1984) found that the P300 component of eventrelated brain potentials was elicited by words printed in large letters in a series of words printed in a smaller typeface. Thus, measures of cortical arousal are also sensitive to manipulations of distinctiveness.

Nonetheless, a definition of distinctiveness based solely on physiological responses is also problematic. As noted above, orientation occurs in response to both novel and significant stimuli. In many manipulations employed in memory experiments, it may be impossible to know whether novelty or significance is responsible for the manipulation's effects on memory. Consider research concerning "flashbulb memories" (e.g., Brown and Kulik, 1977), or memory for "high-priority" events (Schulz, 1971). In both cases, enhanced memory has been attributed to distinctiveness, yet the "distinctive" events were both novel and significant. Measurement of physiological responses does not provide a means of separating manipulations of distinctiveness from manipulations of significance. ${ }^{1}$

Finally, distinctiveness may be defined in terms of ratings of similarity. Recent treatments of conceptual relations (e.g., Gati \& Tversky, 1984, 1987; Ritov, Gati, \& Tversky, 1990) have employed ratings of conceptual relations to estimate the weights assigned to features in a stimulus. However, the selection of features and the weights given to those features are context-bound. For example, Nosofsky (1986) demonstrated that similarity relationships change across experimental tasks. Categorization of concepts was influenced by the attention given to various features. Similarly, Hunt and Elliot (1980) demonstrated that ratings of orthographic distinctiveness can be influenced by the structure of the list. Orthographically unusual words received higher ratings of distinctiveness in the context of orthographically common words than they did in the context of orthographically distinctive words. Thus, even ratings of similarity cannot provide a context-free definition of distinctiveness.

It should be clear that we cannot articulate a contextfree or subject-free operational definition of the concept of distinctiveness. As an alternative, distinctiveness can be viewed as a hypothetical construct, and as such, it can be defined in terms of a set of converging experimental manipulations and observations (Garner, Hake, \& Eriksen, 1956). Thus, a viable approach toward defining distinctiveness is to examine past research, to determine how distinctiveness has been operationalized, and to inspect the set of empirical phenomena that has emerged. From such an examination, we should be able to identify a coherent structure of manipulations and observations and then use this structure as a nomological net (Cronbach \& Meehl, 1955) for the concept distinctiveness. Thus, as with the concept anxiety, a simple operational definition for distinctiveness cannot be offered. Instead, distinctiveness can be defined in terms of a number of different experimental manipulations and their consistent and shared effects on memory.

The definitions of distinctiveness explored above can be employed to organize the diverse phenomena attributed to distinctiveness. The criteria for categorizing these definitions are summarized in the decision tree depicted in Figure 1. Previous researchers have used feature overlap, arousal, ratings of similarity, and numerous other definitions of distinctiveness. Manipulations of distinctiveness that were tied to arousal were separated from other manipulations. In addition, care was taken to distinguish between manipulations leading to arousal indicative of a defensive response and arousal indicative of an orienting response. Only manipulations that involved emotional responses and defensive reactions were classified as manipulations of "emotional distinctiveness." Manipulations associated with the orienting response were passed on for classification in one of the remaining branches of the tree. If an emotional

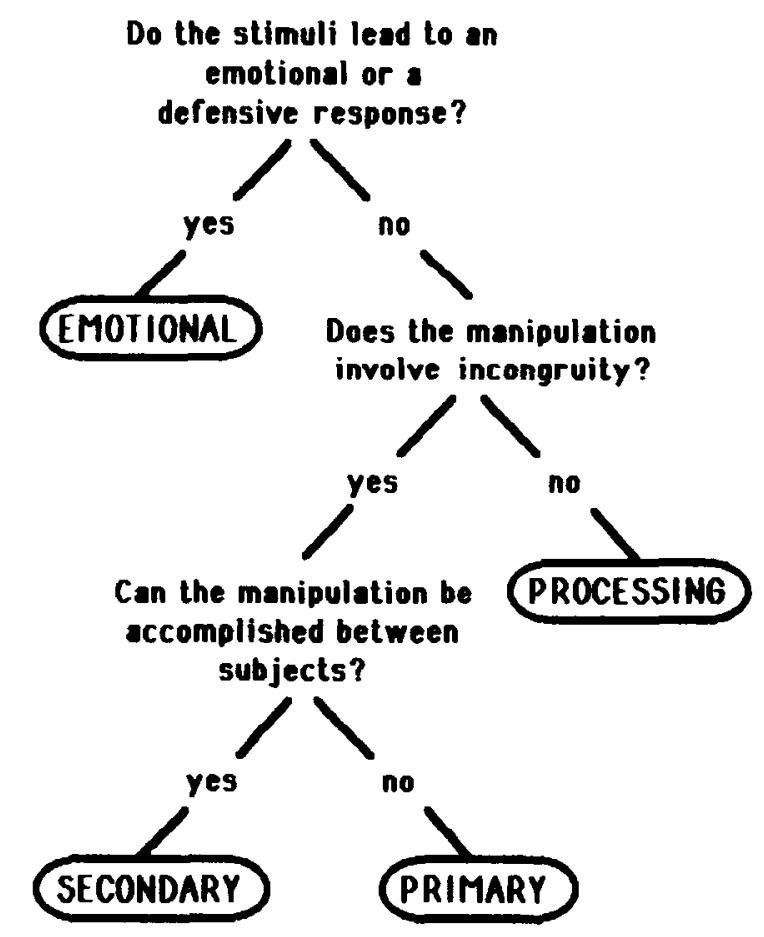

Figure 1. Decision tree for the classification of experiments on the effects of distinctiveness on memory. 
response was not involved, then we considered whether or not the manipulation directly varied conceptual relations as indexed by feature overlap, similarity, or incongruity. If conceptual relations were not involved, the manipulation was classed as a manipulation of "distinctive processes."

Two classes of distinctiveness were tied to manipulations of conceptual relations, and thus distinctiveness was defined in terms of "conceptual incongruity." One of these classes, primary distinctiveness, involved the comparison of a stimulus with information from other recently presented stimuli. Thus, in terms of Ohman's (1979) analysis, distinctiveness resulted from comparison of the stimulus to information still active in primary memory (James, 1890/1950). Such stimuli should lead to an orienting response (Gati \& Ben-Shakhar, 1990). In the second class, secondary distinctiveness, the distinctive item was dissimilar or novel with respect to the larger context of all previous experiences. Thus, distinctiveness was defined relative to the presumed contents of the long-term store, or secondary memory (James, 1890/1950).

Operationally, primary and secondary distinctiveness were separated by focusing on the type of experimental designs that were used to manipulate distinctiveness. Primary distinctiveness must be manipulated in withinsubjects designs in which the same subjects experience both common and distinctive items. ${ }^{2}$ This is because the distinctive item is dissimilar with respect to recently presented stimuli, and presumably with respect to the current set of features in primary memory. However, secondary distinctiveness can be manipulated in either withinsubjects or between-subjects designs, because the stimulus is dissimilar to information retrieved from long-term memory. The classification of manipulations into those that can or cannot be accomplished between subjects is made independently of consideration of the effects of the manipulation on memory. A review of previous research concerning distinctiveness is presented below, organized according to this classification system.

\section{CLASSES OF RESEARCH ON DISTINCTIVENESS}

\section{Overview}

Several variables that influence the effects of distinctiveness on memory will be given special consideration. Foremost among these variables is the type of experimental design. As noted above, some definitions of distinctiveness dictate within-subjects comparisons. However, if both within- and between-subjects designs are possible, one must consider whether or not the effects of distinctiveness are independent of experimental design. One of the puzzles regarding the effects of distinctiveness on memory is that some manipulations that can be accomplished between subjects only influence memory in withinsubjects designs.

A second variable that influences the effects of distinctiveness on memory is the type of memory test. Traditionally, different types of memory tests are thought to require different types of -retrieval processes. For example, recall tests are thought to involve a search of longterm memory not involved in recognition tests of memory (Anderson \& Bower, 1972). Theories of distinctiveness vary in terms of whether or not distinctiveness influences discrimination processes, retrieval processes, or both. If distinctiveness influences search and retrieval processes, the effects of distinctiveness may vary as a function of type of memory test.

The third consideration is the effect of the presence of a distinctive event on the memory for surrounding common events. Several theories of distinctiveness posit that distinctive events receive more attention than common events. These theories can lead to the prediction that memory for material surrounding a distinctive item will be suppressed.

Each of the phenomena discussed below has been attributed explicitly to either a von Restorff effect or the effects of distinctiveness. In addition, a number of phenomena that have not been attributed to distinctiveness fit this framework. These phenomena are briefly discussed at the end of each main section, in subsections entitled Related Phenomena. The four classes of distinctiveness, representative experiments, and distinguishing characteristics are summarized in Table 1.

\section{Emotional Distinctiveness}

William James argued that "an impression may be so exciting emotionally as almost to leave a scar upon the cerebral tissues"' $(1890 / 1950$, p. 670). Manipulations that lead to an emotional response, or to activation of the sympathetic nervous system, will be reviewed in this section. Such manipulations are more likely to lead to what Sokolov (1963) referred to as a defensive reaction, rather than to an orienting response. Nonetheless, many researchers have argued that the effects of emotional stimuli on memory are the result of "distinctiveness" or a "von Restorff effect" (e.g., Christianson \& Loftus, 1987; Loftus \& Burns, 1982; McCloskey et al., 1988). Unfortunately, it is difficult to determine the mechanisms responsible for enhanced memory for emotional stimuli. Many researchers have not even measured the emotional responses of their subjects (e.g., McCloskey et al., 1988), and few researchers have distinguished between arousal indicative of a defensive response and arousal indicative of an orienting response.

Nude pictures. Researchers have inserted the picture of a nude in a series of more typical magazine pictures (N. R. Ellis, Detterman, Runcie, McCarver, \& Craig, 1971). Recall and recognition of the nude picture were greater than memory for a typical picture in the same serial position in a control list. In addition, recall and recognition of pictures following the nude were suppressed. Unfortunately, correct recall and recognition performance in the N. R. Ellis et al. (1971) study could be based simply on the memory that a nude was presented. Memory for specific details in the pictures was not assessed.

Physiological responses to sexually arousing materials are complex and include a biphasic heart-rate response 
(Rosen \& Beck, 1988). During the first second of exposure to a nude picture, heart-rate deceleration characteristic of the orienting response is observed. This is followed by heart-rate acceleration during the next $3 \mathrm{sec}$ of exposure. Other physiological responses include pupillary dilations and vasoconstriction. Obviously, more is going on in response to sexually arousing stimuli than an orienting response to a novel or significant stimulus.

Trauma. In the second area of research concerning emotional events and memory, researchers have employed traumatic materials, such as a videotape of a boy being shot in the face, or a series of slides containing an automobile accident in which a young boy is injured (Christianson \& Loftus, 1987; Loftus \& Burns, 1982). Recall and recognition of details in a traumatic scene were worse than memory for the same details in nonviolent versions of the scenes (Clifford \& Hollin, 1981; Loftus \& Burns, 1982). For example, in the Loftus and Burns (1982) study, memory for the number on a football jersey worn by a boy was worse when the boy was shot than when the boy was unhurt. Christianson and Loftus (1987) demonstrated that memory for peripheral details was worse following presentation of a traumatic as opposed to a nontraumatic series of slides. However, the traumatic version led to better recall of the gist of the traumatic slides, and to better memory for the essence of the slides on a delayed memory test, than did the nontraumatic version (Christianson \& Loftus, 1987).

A recent investigation reported by Heuer and Reisberg (1990) demonstrates the difficulty in interpreting the effects of traumatic stimuli on memory in terms of a theory of distinctiveness. Heuer and Reisberg compared memory for an emotional story in which pictures of a surgical operation were shown with memory for a similar story in which pictures of an automobile repair were shown. The emotional version led to enhanced memory for both central and peripheral details. The important new piece of information in this study was an analysis of heart rate during presentation of the material. The emotional story led to heart-rate deceleration, a reaction characteristic of an orienting response. Depending on the nature of the stimuli employed, some of the effects of trauma reported above may result from emotional distress and a defensive reaction, whereas other effects may result from the increased attention associated with the orienting response. The pattern of results in which memory for central details is enhanced, and in which memory for peripheral details is suppressed, may only occur when a defensive reaction is elicited. It seems inappropriate to use "distinctiveness" to explain the results of manipulations that lead to defen-

Table 1

Classification, Representative Experiments, and Distinguishing Characteristics of Many Types of Distinctiveness

\begin{tabular}{lll}
\hline Types of Manipulations & \multicolumn{1}{c}{ Representative Experiments } & Distinguishing Characteristics \\
\hline & & \multicolumn{1}{c}{ EMOTIONAL DISTINCTIVENESS } \\
Nudes & Ellis et al. (1971) & Activation of the sympathetic nervous system; paradoxical effects on \\
Trauma & Loftus \& Burns (1982) & memory in which memory for detail may be lost but memory for gist is \\
Flashbulb memories & Brown \& Kulik (1977) & enhanced. \\
Humor & Kaplan \& Pascoe (1977) &
\end{tabular}

Humor

Kaplan \& Pascoe (1977)

Related Phenomena

Arousal

Depression

Perceptual

Category

High-priority items

Encoding task

Consistency effect

Typicality effect

Predictability

Distinctive orthography

Unusual faces

Bizarre imagery

Generation effect

Word-frequency effect Inverted text

Expectation-violation

Causal relatedness

Depth of processing Concreteness effect Long-term modality effect

Clark et al. (1983)

Ellis et al. (1984)

McLaughlin (1968)

Schmidt (1985)

Schulz (1971)

Bird (1980)

Pezdek et al. (1989)

Bower et al. (1979)

O'Brien \& Myers (1985)

\section{SECONDARY DISTINCTIVENESS}

Hunt \& Elliot (1980)

Going \& Read (1974)

McDaniel \& Einstein (1986)

Slamecka \& Graf (1978)

Can be operationalized in either within- or between-subjects designs; effects are confined to within-subjects designs; effects of distinctiveness are a function of type of memory test.

Related Phenomena

Gregg (1976)

Kolers (1975)

Hirshman (1988)

Keenan et al. (1984)

\section{PROCESSING DISTINCTIVENESS}

Craik \& Tulving (1975)

Marschark \& Hunt (1989)

Gathercole \& Conway (1988)
Can be operationalized in either within- or between-subjects designs; effects are found in both within- and between-subjects designs; study-test congruence is important. 
sive responses, orienting responses, suppressed memory for details, and enhanced memory for details.

Flashbulb memory. Flashbulb memories are the vivid recollections many of us have of the circumstances surrounding our discovering shocking pieces of news (Brown \& Kulik, 1977). Events such as the assassination of President Kennedy or the explosion of the space shuttle Challenger are examples of emotional events leading to reports of flashbulb memories. Researchers have reported that increased affect is associated with more detailed accounts of traumatic experiences (Bohannon, 1988; Pillemer, 1984). However, some researchers have questioned whether the events reported from these experiences are accurate recollections or merely reconstructions (McCloskey et al., 1988, Neisser, 1982). Bohannon (1988) reported that students who were upset by the explosion of the space shuttle Challenger remember more details of the disaster than do students who were not upset. Further support for the role of emotion in producing enhanced memory was reported by Christianson (1989), who interviewed men and women living in Sweden about the assassination of the Swedish prime minister Olof Palme. Subjects were asked to describe the circumstances surrounding their learning of the assassination as well as those surrounding a personal control event (activities on the Saturday afternoon prior to an initial interview). On a delayed test, recall of the flashbulb experience was better than recall of the control event. However, Christianson (1989) failed to find any relation between the strength of the emotional response and the consistency of reported details of the flashbulb memories.

The research on flashbulb memories suggests that strong affect can increase recall of information pertaining to the shocking discovery. However, it is unclear whether these effects should be attributed to the emotional response elicited by the stimulus or to some other factor. Several researchers have argued that the flashbulb memories are the result of the "significance" of the event (Pillemer, 1990). Alternatively, perhaps good memory for events like the explosion of the space shuttle should be attributed to the fact that the event was unexpected (McCloskey et al., 1988) and thus was incongruent with active cognitive structures.

Humor. In addition to nudity, emotional trauma, and shocking news, humor can evoke an affective response. McGhee (1983) summarized a variety of physiological responses to humor that are indicative of increased arousal and activation of the sympathetic nervous system. Thus, one might expect memory for humorous events to behave in the same manner as memory for other emotional events. Unfortunately, very little research concerning the effects of humor on memory has been reported. Kaplan and Pascoe (1977) compared memory for lectures that contained either serious or humorous examples. Certain target concepts were illustrated with humorous examples to one section of introductory psychology, and with serious examples to another section. Nontarget concepts were pre- sented seriously to both groups. On an immediate test, memory for humorously presented targets was no better than memory for seriously presented targets. However, nontarget concepts were more poorly remembered by students who heard the lecture containing humorous examples! On a delayed test 6 weeks later, the group that heard the humorous targets remembered those concepts better than did the group that heard the seriously presented concepts. Memory for nontarget concepts was not affected by humor on the delayed test. Similar results were reported by Kintsch and Bates (1977). They compared memory for topic statements, details, and extraneous remarks and jokes presented during a lecture. Memory for both the meaning and the surface features of the extraneous remarks and jokes exceeded memory for the other types of information. These results were attributed to a von Restorff effect (Kintsch \& Bates, 1977, pp. 156-157).

Schmidt (1990a) compared memory for humorous and nonhumorous versions of the same sentences. A greater number of humorous sentences as opposed to nonhumorous sentences were recalled. However, this result was limited to within-subjects manipulations of sentence humor, as well as to measures of recall of sentence gist rather than measures of memory for sentence detail. The effects of humor on memory seem to fit the pattern found in other research concerning memory for emotional material. If the humorous statement itself is viewed as the central material, and if other lecture material or other sentences in a list are viewed as the peripheral material, then humor enhances memory for the central material and suppresses memory for peripheral information.

Related phenomena. The role of emotion in memory has also been studied in experiments in which the mood or arousal of the subject is manipulated prior to presentation of the material. For example, Clark, Milberg, and Ross (1983) manipulated arousal by asking subjects to exercise prior to study and/or test. This manipulation led to statedependent memory effects; memory performance was greatest when memory was tested in the state of arousal (normal vs. high) that was present during study. In similar research, experimenters have manipulated mood by inducing either a depressed or a normal state $(\mathrm{H}$. C. Ellis, Thomas, \& Rodriguez, 1984). Depressive moods may lead to impaired memory, particularly for complex materials (H. C. Ellis, Thomas, McFarland, \& Lane, 1985). In addition, the manipulation of mood has led to state-dependent memory effects (Bower, 1981).

Craik and Blankstein (1975) reviewed research concerning the effects of phasic arousal increments on retention. They concluded that higher arousal during presentation is generally associated with better retention on delayed memory tests. Several studies in this area employed materials very similar in emotional content to the nudes and traumatic scenes previously discussed. For example, Kleinsmith and Kaplan (1963) reported that on a delayed test, high-arousal words such as RAPE and VOMTT were remembered better than were low-arousal words. 
Maltzman, Kantor, and Langdon (1966) provided evidence that the physiological response to such stimuli was a defensive response, not an orienting response.

Summary of emotional distinctiveness. Events that produce strong emotional responses are generally remembered well. The results are less clear with respect to what aspects of memory for an emotional event are enhanced. Some researchers have reported suppressed memory for surrounding or peripheral information (N. R. Ellis et al., 1971; Kaplan \& Pascoe, 1977; Loftus \& Burns, 1982), whereas other researchers have reported enhanced memory for the context of the event (Bohannon, 1988; Brown \& Kulik, 1977; Christianson, 1989; Heuer \& Reisberg, 1990). The effects of emotion on memory are further complicated by the fact that these effects are to some extent state-dependent (e.g., Bower, 1981; Clark et al., 1983), are influenced by the strength of the emotional response (H. C. Ellis, 1985), and are asymmetrical for positive and negative moods (Isen, 1985). Furthermore, many researchers employing arousing stimuli in memory experiments have failed to differentiate between defensive and orienting responses, and have generally failed to address the potential interactive effects of arousal and emotion (Craik \& Blankstein, 1975). Therefore, the many manipulations employed to investigate the role of affect in memory do not share a common operational definition, and these manipulations do not lead to a common pattern of results. Applying the von Restorff label to the enhanced memory for emotional events, or "explaining" these effects by invoking the concept of "distinctiveness," falls far short of an adequate explanation or description of the impact of affect on memory.

\section{Primary Distinctiveness}

Primary distinctiveness, which is closely tied to Murphy and Medin's (1985) notion of conceptual coherence, includes all three types of von Restorff phenomena in Wallace's (1965) classification. By this definition, the structure of the to-be-remembered material activates an overall conceptual organization or framework. One or more items in the material do not fit this overall structure, and thus these items are "distinctive." Distinctiveness is defined relative to the immediately surrounding context, and presumably to the contents of working memory.

Perceptual distinctiveness. Perceptually distinctive items contain salient surface features that set the item apart from surrounding material. A single item printed in red in a list of items printed in black is an example of perceptual distinctiveness. This category of distinctiveness is what Wallace (1965) identified as his first type of von Restorff phenomena. The effects of perceptual distinctiveness are often found in recall but not in recognition (McLaughlin, 1968; van Dam, Peeck, Brinkerink, \& Gorter, 1974). However, Karis et al. (1984) reported that physically distinctive items were recognized more quickly than common items were. Perceptually distinctive items are often clustered in recall (Bruce \& Gaines, 1976), but their presence apparently has no effect on recall or recogni- tion of surrounding background items (Bruce \& Gaines, 1976; McLaughlin, 1968; van Dam et al., 1974).

Category distinctiveness. In category distinctiveness, the material is not physically different from surrounding material. Instead, the distinctive item belongs to a different conceptual category. For example, embedding the name of an animal in a list of names of countries leads to better recall and recognition of the animal name than does embedding the name in a list of other animal names (Schmidt, 1985). Another example of category distinctiveness is the presentation of a three-letter noun in a list of nonsense CVCs (Jenkins \& Postman, 1948). Category distinctiveness is most similar to Wallace's second type of von Restorff manipulation. Categorically distinctive items are better recalled, clustered more in recall, and better recognized than items from homogeneous lists (Hunt \& Mitchell, 1982; Schmidt, 1985). Surrounding background items are more poorly recalled (Hunt \& Mitchell, 1982; Jenkins \& Postman, 1948; Schmidt, 1985), but not more poorly recognized (Schmidt, 1985), when lists contain distinctive items than when lists are homogeneous.

High-priority events. Subjects are sometimes asked to pay special attention to, and to be sure to remember, specific target items in a list. The signal identifying the high-priority item has been either a tone presented immediately following the item (Waugh, 1969), or the item's membership in a specific conceptual category (e.g., famous names; see Schulz, 1971; Tulving, 1969). Highpriority events are recalled better (Tulving, 1969; Waugh, 1969) and recognized better (Schulz, 1971) than are appropriate control items. In addition, the presence of highpriority items has a negative effect on the recall and recognition of surrounding background items (Schulz, 1971; Tulving, 1969; Waugh, 1969).

Priority effects are usually considered as yet another example of distinctiveness (see, e.g., Christianson \& Loftus, 1987; N. R. Ellis et al., 1971; and Waugh, 1969). Operationally, priority manipulations are very similar to physical and category distinctiveness. A tone signaling a priority item makes that item physically distinctive, and priority items that are famous names are members of a distinctive category. However, several factors distinguish the priority manipulation from physical and category distinctiveness. First, the subjects are explicitly instructed to pay attention to the high-priority items, and they are sometimes asked to recall high-priority items first (Schulz, 1971; Tulving, 1969). Second, the negative effects of high-priority items on the recall and recognition of background items are unlike effects found with physical and category distinctiveness. These effects of priority may be the result of the combined effects of novelty and significance identified by Gati and Ben-Shakhar (1990).

Encoding-task distinctiveness. Another type of primary distinctiveness is defined in terms of the encoding task performed on material in a list. Bird (1980) investigated the effects of pleasantness and word-length judgments on incidental memory. Unique encoding tasks were created by asking subjects to perform one type of judg- 
ment on all the items in a list save one. Subjects performed the second orienting task on the isolated item. Independent of processing task, isolation enhanced recall relative to lists in which all items received the same processing. However, unlike the effects of category distinctiveness, encoding-task distinctiveness did not affect the recall of background items (Bird, 1980).

Consistency effect. Items can be presented in a scene that are either consistent or inconsistent with the subjects' generalized knowledge (or schema) of the scene. Items inconsistent with these knowledge structures appear to be recalled and recognized better than consistent items are (Friedman, 1979; Hock, Romanski, Galie, \& Williams, 1978). In a recent example of this "consistency effect," Pezdek et al. (1989) had subjects view either a graduate student's office or a preschool classroom. In one condition, items that were typical in one setting (an ashtray in an office) were presented in the other setting. Recall and recognition of these inconsistent items was better than memory for the same items in the appropriate setting. In addition, the recognition test required subjects to discriminate between tokens of the target items. For example, the test required subjects to remember whether an octagonal glass ashtray or a round tin ashtray was present in the setting. Memory for this detailed token information was enhanced by inconsistency. These effects of consistency are in direct contrast with the effects of trauma (see, e.g., Loftus \& Burns, 1982) on memory.

Related phenomena. Findings similar to the consistency effect have been reported in memory for scripted (Bower, Black, \& Turner, 1979; Graesser, Gordon, \& Sawyer, 1979) and pictured (Goodman, 1980) activities. Recognition memory for material atypical of a scripted or a pictured activity is superior to recognition memory for typical actions. It is tempting to attribute these effects of typicality to distinctiveness. However, typicality has not been studied as a univariate dimension; rather, it includes variables such as the frequency, disruptiveness, and irrelevance of activities (Bower et al., 1979). Given the variety of ways in which typicality has been defined, and the complexity of the effects of typicality on memory, great caution should be adopted before accepting the typicality effect as an example of the effects of distinctiveness on memory.

A second phenomenon similar to primary distinctiveness is the effect of text predictability reported by O'Brien and Myers (1985). A single target word presented in a paragraph was either predictable or not from preceding text. Reading times were longer, and memory performance was superior, for the unpredictable targets relative to predictable targets.

Summary of primary distinctiveness. Research in this area generally fits into a theoretical framework in which distinctive items are those that are incongruent with an active cognitive structure. Presumably, the salient features of the items do not match those of preceding items, and thus the item is likely to lead to an orienting-attention response. Inconsistent effects of manipulations in this class may be explained by the degree of incongruity and the resulting magnitude of the orienting-attention response. A continuum of the effects of primary distinctiveness can be identified in which distinctive items display enhanced recall but not recognition (McLaughlin, 1968), enhanced recall and recognition with negative effects on background recall only (Schmidt, 1985), and enhanced recall and recognition with negative effects on background recall and recognition (Schulz, 1971). Theories of distinctiveness must explain why recall reveals the effects of distinctiveness more readily than recognition.

\section{Secondary Distinctiveness}

The definition of distinctiveness in this class is tied to information stored in permanent memory. Thus, distinctive items are atypical members of a conceptual class, or they describe semantic relations between concepts that are atypical of the constituent concepts. Secondary distinctiveness should follow the principles of categorization described by Rosch and her associates (e.g., Rosch, 1973; Rosch \& Mervis, 1975). It is important to note that in secondary distinctiveness, unlike primary distinctiveness, the distinctive items do not form their own conceptual group. Instead, distinctive items are peripheral members of a natural category.

The distinction between primary and secondary distinctiveness is potentially confusing. Both types of distinctiveness may involve the same kind of conceptual incongruity. For example, the bizarre sentence The dog rode the bicycle down the street is distinctive, because dogs do not typically ride bicycles. In terms of conceptual incongruity, the predicate rode the bicycle is incongruent with the conceptual information concerning dog. For the sake of comparison, consider the manipulation of category distinctiveness in the following list of items: $d o g$, cat, bird, bicycle, fish. Once again, the word bicycle is incongruent with conceptual information concerning $d o g$. However, the bizarre sentence involves secondary distinctiveness because one can construct a set of materials composed only of bizarre sentences, and because a bizarre sentence is bizarre independently of its context. This is because the functional unit, the sentence, is incongruent with information stored in secondary memory. Category distinctiveness was classed as primary distinctiveness because incongruity is created by the surrounding list items, and thus the manipulation must be made within subjects. In this case, the functional unit is the word, and the word bicycle is incongruent with the content of primary memory.

Orthographic distinctiveness. Orthographically distinctive words (e.g., llama) contain letter combinations or have visual appearances that make them atypical members of the category "English words." Materials are selected by asking subjects to use a Likert-type scale to rate the physical characteristics of words from not distinctive to very distinctive (Kausler, 1973; Zechmeister, 1969). Words that are rated as distinctive are remembered better than words rated as not distinctive (Hunt \& Elliot, 
1980; Hunt \& Mitchell, 1982; Kausler, 1973). The effects of orthographic distinctiveness on word memory are found in both recognition and free recall (Hunt \& Elliot, 1980; Zechmeister, 1972), but they are confined to mixedlists designs (Hunt \& Elliot, 1980; for an exception, see Kausler, 1973). Hunt and Mitchell (1982) found little evidence of clustering of orthographically distinctive items. Orthographic distinctiveness does not appear to have an effect on the recall (Hunt \& Mitchell, 1982) or recogni tion (Hunt \& Elliot, 1980) of the orthographically common items in a mixed list.

Unusual faces. Facial distinctiveness is operationalized much as orthographic distinctiveness. That is, subjects are shown a group of faces and are asked to rate them for "typicality" (Light, Kayra-Stuart, \& Hollander, 1979) or "uniqueness" (Going \& Read, 1974). Cohen and Carr (1975) asked their subjects to rank a set of faces from "most to least distinctive." Recognition memory for distinctive faces is superior to recognition for more common faces (Cohen \& Carr, 1975; Going \& Read, 1974; Light et al., 1979). In each of the studies listed above, facial distinctiveness was manipulated in within-subjects, mixedlist designs.

Bizarre imagery. In a typical experiment on bizarre imagery, subjects are asked to form interactive images of concrete noun pairs. In a bizarre condition, subjects are further instructed to make those images strange or unusual. For example, Wollen, Weber, and Lowry (1972) asked subjects to form an image of a cigar and a piano. In the interactive-bizarre condition, they were instructed to form an image of the piano smoking the cigar. In the interactive-nonbizarre group, subjects formed images of a cigar resting on the edge of the piano. Similar manipulations have required subjects to form images of the relations between nouns in a sentence $(\mathrm{McD}$ aniel \& Einstein, 1986). Two versions of each sentence were created, a nonbizarre version in which the nouns interacted in characteristic fashion (e.g., The dog chased the bicycle down the street), and a bizarre version (e.g., The dog rode the bicycle down the street).

Recent evidence suggests that in mixed-list designs, bizarre imagery enhances free recall (Einstein, McDaniel, \& Lackey, 1989; McDaniel \& Einstein, 1986). Enhanced recall of bizarre materials occurs at the expense of recall of common materials in the same list (McDaniel \& Einstein, 1986). Special conditions are required to produce enhanced memory for bizarre sentences in between-list designs. Typically, memory for a list containing only bizarre items is not better than memory for a list containing only common items. However, McDaniel and Einstein (1986) had subjects read two lists prior to an unexpected recall test. The first list contained bizarre sentences for one group of subjects and common sentences for a second group. For both groups, the second list contained common sentences. First-list recall was better for the group that read the bizarre sentences. Apparently, bizarreness enhances sentence recall only if the bi zarre material is presented in the context of some common material. These results led McDaniel and Einstein
(1986) (see also Einstein \& McDaniel, 1987) to attribute the effects of bizarre imagery on recall to distinctiveness.

Nonetheless, there are a number of ways in which the effects of bizarre imagery on memory are unlike the effects of other types of secondary distinctiveness. The effects of bizarre materials can only be found when subjects are asked to form images and rate the vividness of those images, and not when they are asked to rate the degree to which the relation among the items in a sentence is unusual (McDaniel \& Einstein, 1986, Experiment 2). Hirshman, Whelley, and Palij (1989) have argued that subjects must be "surprised" by a bizarre sentence for bizarreness to enhance memory. Also, bizarre imagery enhances the access to sentences but not sentence integration as measured by cued recall or recall of items given successful sentence recall (Einstein \& McDaniel, 1987). Finally, unlike other types of distinctiveness, bizarre imagery does not appear to aid recognition performance (Einstein et al., 1989; McDaniel \& Einstein, 1986).

The generation effect. In a typical generation task, subjects are given a word or word pair with several of the letters replaced with blanks (e.g., fruit-ap_l_). The subjects' task is to complete the word and prepare for a memory test. Under a wide variety of conditions, in both recall and recognition, memory for generated words is superior to memory for intact words (Slamecka \& Graf, 1978). In the typical list structure employed in generation experiments, half of the items are intact and half of the items must be generated. With this list structure, the generation effect should be viewed as an example of secondary distinctiveness. That is, the functional unit (the word) does not match information contained in the permanent memory system.

Several researchers have attempted to explain the generation effect by invoking the concept of distinctiveness (Begg et al., 1989; Kinoshita, 1989; Schmidt, 1988, 1991). In support of this explanation, researchers have noted that the generation effect in free recall is more robust in mixed-list designs than it is in between-list designs (Begg \& Snider, 1987, Slamecka \& Katsaiti, 1987). Also, like the effects of bizarre imagery, generation of some items in a mixed list appears to have a negative effect on the recall of the read items in the list (Begg \& Snider, 1987; Begg et al., 1989; Schmidt, 1990b, Slamecka \& Katsaiti, 1987). These results indicate a strong similarity between the generation effect and other types of secondary distinctiveness.

Nonetheless, several characteristics set the generation effect apart from other types of secondary distinctiveness. First, words to be generated may actually share features (e.g., blanks replacing letters) and thus form their own conceptual group. As a result, when several generated items are embedded in a list of read items, the generated items are clustered in recall (Schmidt, 1991). Second, contrary to the conclusions of Begg and Snider (1987) and Slamecka and Katsaiti (1987), the generation effect has been reported in some between-subjects designs (Hirsh- 
man \& Bjork, 1988; McDaniel, Waddill, \& Einstein, 1988), a result inconsistent with the effects of other types of secondary distinctiveness. Finally, Schmidt (1991), who compared the generation effect with category distinctiveness, encoding task distinctiveness, and orthographic distinctiveness, found important differences between each type of distinctiveness and the generation effect. It appears that word generation is unlike other manipulations of distinctiveness.

Related phenomena. No discussion of secondary distinctiveness would be complete without inclusion of the word-frequency effects in recall and recognition. Word frequency has paradoxical effects on memory: low-frequency words are recognized better than high-frequency words, whereas high-frequency words are recalled better than low-frequency words (see Gregg, 1976, for a review). However, like the effects of secondary distinctiveness, the word-frequency effect in recall is influenced by list structure. Low-frequency words are recalled better than high-frequency words in mixed-list designs (Duncan, 1974; Gregg, 1976; Gregg, Montgomery, \& Castano, 1980; May \& Tryk, 1970).

Kolers's research on inverted text (Kolers, 1973, 1974, 1975; Kolers \& Ostry, 1974) may provide another example of secondary distinctiveness. When college students were asked to read sentences with inverted topography and sentences that were oriented normally, the inverted sentences were recognized better than the normally oriented sentences. In addition, students unpracticed at reading inverted text remembered inverted sentences better than practiced students did (Kolers, 1975). Surprisingly, all the research that we could uncover concerning memory for inverted text employed within-subjects designs, providing a similarity between this phenomenon and secondary distinctiveness.

In a third phenomenon similar to secondary distinctiveness, Hirshman (1988) reported that weakly related word pairs (e.g., patch-lettuce) were recalled better than strongly related word pairs (e.g., cabbage-lettuce). Superior memory for weakly related word pairs occurred only when each of the following conditions was met: (1) a mixedlist design was employed; (2) the number of weakly related pairs was not a clear majority; and (3) a free recall but not a cued recall test was employed. Hirshman (1988) argued that this "expectation-violation effect" resulted because subjects in a mixed-list design searched for a strong associative relation between members of weakly associated pairs and failed to find such a relation.

In a fourth phenomenon related to secondary distinctiveness, researchers have varied the causal connections between sentences in a paragraph (Keenan, Baillet, \& Brow, 1984; Myers, Shinjo, \& Duffy, 1987). Reading times increased monotonically as the causal connection between sentences declined. However, sentence recall first increased as the causal connection between sentences decreased, and then decreased as the connection became obscure. Although within-subjects designs have been exclusively employed in this paradigm, one could feasibly manipulate causal relations in a between-subjects design.
Summary of secondary distinctiveness. This class of distinctiveness is unique in that distinctiveness can be manipulated in either within- or between-subjects designs, but its effects appear to be confined to within-subjects designs. Two exceptions to this rule are the generation effect and the word-frequency effect on recognition performance. Thus the effects of secondary distinctiveness depend jointly on how distinctiveness is defined and on the type of experimental design employed. Provided that a mixedlist design is used, enhanced recall and recognition occurs for orthographically distinctive words, infrequent words, generated words, and sentences of intermediate causal relatedness. However, the effects of bizarre imagery and expectation violation are confined to free recall.

\section{Distinctive Processes}

In this class of distinctiveness, different processes evoked by different tasks or materials are thought to lead to memory traces varying in distinctiveness. Manipulations that have been linked to distinctiveness and fail to meet any of the criteria in the current classification (see Figure 1) end up in this class by default. Like secondary distinctiveness, processing distinctiveness can be manipulated in either within- or between-subjects designs. However, unlike secondary distinctiveness, distinctive processes appear to enhance memory in both types of designs. Three examples of distinctive processes are reviewed below.

Depth of processing. Much of the extensive literature concerning depth of processing (see Cermak \& Craik, 1979 , for a review) can be placed in this category. Tasks requiring a semantic analysis were thought to lead to a more distinctive memory trace, a trace that is less like previous encodings, than were tasks requiring phonetic or structural analysis (Eysenck, 1979). Although the effects of depth of processing are often studied in mixedlist designs (e.g., Craik \& Tulving, 1975), the effects are equally robust in between-subjects designs (e.g., Johnston \& Jenkins, 1971). The effects of increases in depth of processing are similar on recall and recognition tests of memory (Craik \& Tulving, 1975).

Research concerning "task appropriate processing" (Morris, Bransford, \& Franks, 1977; Stein, 1978) has indicated that greater depth of processing does not necessarily lead to better memory performance. For example, a case-processing task led to better memory for case information than a semantic processing task did (Stein, 1978). Apparently, the type of information stored as well as the distinctiveness of the information influences memory performance. A semantic processing task may lead to a more unique trace than a structural processing task, but that trace may not contain the information that is necessary for good performance on all types of memory tests.

Concreteness effect. Memory performance is better for concrete words than for abstract words in free recall, cued recall, and recognition (Paivio \& Csapo, 1969). Recently, Marschark and Hunt (1989; Marschark et al., 1987) concluded that the concreteness effect was the result of distinctiveness. They found that concrete word pairs led to better memory than abstract pairs did, when recall of the second 
member of the pair was cued with the first member. However, the concreteness effect was eliminated or attenuated when free recall of the word pairs was required. In addition, Marschark (1985) reported that the concreteness effect was not obtained with prose materials (but see Ransdell \& Fischler, 1989). These results are difficult to explain with the dual coding theory (Paivio, 1971), which predicts consistent superior recall of concrete material. Concrete words should not generally lead to an emotional response or incongruity, so manipulations of concreteness are classified with processing definitions of distinctiveness.

The distinctiveness interpretation of the concreteness effect illustrates the excessive versatility of distinctiveness as a theoretical construct. Compare the effects of distinctiveness on memory when "distinctiveness" is operationalized as bizarre imagery and the effects of "distinctiveness" when it is operationalized as concrete stimuli. In both cases, visual imagery is thought to be an important part of the encoding process. However, bizarre imagery enhances free recall but not cued recall or recognition, and concreteness enhances cued recall and recognition but not free recall. The effects of bizarreness are found only in mixed-list designs, but the effects of concreteness are found in both types of designs (Marschark \& Hunt, 1989). Nonetheless, researchers have attributed both effects to distinctiveness.

Long-term modality effect. Conway and Gathercole have reported a series of studies demonstrating the effects of the input modality on the long-term retention of words (Conway \& Gathercole, 1987, 1990; Gathercole $\&$ Conway, 1988). Input modality has reliable effects on long-term retention as measured on recall and recognition tests, and the effects are found in both within- and between-subjects designs (Gathercole \& Conway, 1988). Thus, long-term modality effects occur in situations similar to those in which other processing definitions of distinctiveness apply.

Unfortunately, the term "distinctiveness" has been used rather loosely in explanations of the long-term modality effect. Conway and Gathercole (1987) demonstrated that when subjects speak aloud visually presented words, retention is better than it is when subjects covertly read or mouth the words. Conway and Gathercole interpreted these results in terms of Gardiner and Gregg's (1979) theory that auditory information is temporally more distinct than visual information. A second series of studies required a modification of this view. Gathercole and Conway (1988) found that spoken words were remembered better than auditorially presented words and visually presented unspoken words. Auditory presentation did not lead to reliably better memory than visual presentation did. These results ruled out audition as the central cause of long-term modality effects. The authors argued that vocalization led to self-generated cues, and that these cues, together with the auditory information, led to a more distinctive memory than did covert reading of the to-beremembered material. A third series of studies led to yet another interpretation. Conway and Gathercole (1990) found that hearing and writing a presented word produced better memory than did simply hearing a word, whereas reading and writing a word led to only modest gains in memory when compared with reading alone. These results were explained in terms of the "translation hypothesis," according to which "input activities that necessitate translations between different processing domains result in more distinctive memory traces than non-translated input activities, and more distinctive memory representations lead to enhanced memory performance"' (p. 524). Across this series of studies, "distinctiveness" was used to explain differences between audition and vision, the effects of self-generated cues, and the effects of crossmodality processing. An index of distinctiveness independent of memory performance was never offered. It seems that enhanced memory was used to determine which encoding tasks produced distinctive memories, and that distinctiveness was used to explain the effects of different encoding tasks on memory.

Summary of distinctive processes. Encoding processes that lead to a more precise memory trace, a trace that effectively distinguishes a learning episode from other information, lead to better memory than do less discriminating processes. The effects of distinctive processes on memory are found in both within- and between-subjects designs, and they are found on both recall and recognition tests of memory.

When distinctiveness is defined in terms of distinctive processes, the problems associated with a theory of memory based on distinctiveness are most apparent. The depth-of-processing approach to memory was severely criticized because researchers failed to provide a means to determine "depth" independent of memory performance (Baddely, 1978; Eysenck, 1978). Hunt and Elliot (1980) promised that the distinctiveness hypothesis would be less susceptible to this criticism. They argued that an "independent index of distinctiveness becomes readily available through the scaling of the particular properties of interest' (p. 71). However, scalings of distinctiveness have not been employed in definitions of distinctive processes. In addition, it seems inappropriate to ask subjects to rate the relative distinctiveness of encoding tasks. For example, which type of processing will lead to a more distinctive memory trace-writing an auditorially presented word, or speaking a visually presented word? Which is more distinctive-structural processing of a concrete word, or semantic processing of an abstract word? It is difficult to determine a priori which types of processing lead to more distinctive memory traces. Previous researchers have employed enhanced memory as an index of processing distinctiveness, leading to circular explanations of memory performance.

\section{Summary of the Four Classes of Distinctiveness}

Sixteen different phenomena that have been attributed to distinctiveness have been reviewed above. Each phenomenon represented a different operational definition of distinctiveness, and many different patterns of results have 
been reported. Distinctiveness has been defined in terms of the emotional response to the stimulus, a comparison of the stimulus with other recent stimuli, a comparison of the stimulus with the contents of long-term memory, and the types of processes employed to encode the stimulus. Distinctiveness appears to enhance memory for gist but not memory for detail (Christianson \& Loftus, 1987), and yet enhance memory for both type and token information (Pezdek et al., 1989). The effects of distinctiveness can be observed on recall but not recognition tests (McDaniel \& Einstein, 1986; McLaughlin, 1968). However, when distinctiveness is defined in terms of concreteness (Marschark \& Hunt, 1989) or word frequency (Gregg, 1976), distinctiveness enhances recognition but not free recall. Distinctive events sometimes enhance (Brown \& Kulik, 1977) and sometimes suppress recall of surrounding events (N. R. Ellis et al., 1971). Some researchers have reported effects of distinctiveness independent of type of experimental design (Gathercole \& Conway, 1987; Marschark \& Hunt, 1989), whereas other researchers have found that distinctiveness enhances memory only in within-subjects designs (Hunt \& Elliot, 1980; McDaniel \& Einstein, 1986). The concept of distinctiveness, as it has been used in the past, is quite powerful, and able to explain almost any pattern of results.

The contradictory effects of distinctiveness on memory can be partially redressed if the many definitions of distinctiveness are broken down into separate classes. By focusing on operational definitions, I have identified four different classes of distinctiveness, and the patterns of results are generally consistent within each class. It could be argued that for each type of distinctiveness identified above, the resulting memory trace contains features that distinguish the material from other items in memory. As such, these manipulations all lead to distinctive memory traces. However, this argument is vacuous, containing little more than a statement that distinctiveness is associated with distinctive memory traces. In addition, this argument fails to explain why different definitions of distinctiveness lead to different patterns of results. A more reasonable conclusion is that the many different operational definitions of distinctiveness, and the many different patterns of results, do not converge on a single hypothetical construct. Rather, the classes of manipulations identified above, and their effects on memory performance, are indicative of different mnemonic processes.

\section{THEORETICAL ALTERNATIVES}

The preceding review has been intentionally atheoretical, with the discussion tied to operational definitions rather than theoretical constructs. Perhaps a memory theory exists that has at its heart the concept of distinctiveness and is able to encompass the many operational definitions and the varied patterns of results reported above. In the following section, four theoretical approaches to distinctiveness are discussed in an attempt to rescue the unitary view of distinctiveness. First, approaches based upon operations performed during encoding are presented, followed by retrieval approaches, and concluding with two combined encoding and retrieval models of distinctiveness. As noted by Schmidt (1985), very little research has been directed at discriminating between the theoretical alternatives. The purpose of the present review is to demonstrate that a compelling theory of distinctiveness has not been developed. In the absence of a compelling theory, a common definition, or a cogent structure of empirical phenomena, the concept of distinctiveness in memory is of little heuristic value.

\section{Encoding Explanations}

A number of theoretical alternatives focus on processes occurring during the encoding of distinctive events. Distinctive events may receive a greater number of rehearsals than common events receive (Rundus, 1971). Alternatively, distinctive items may be processed to a greater "depth" (Craik \& Lockhart, 1972) than common items are. A third hypothesis is that distinctive events attract attention (Green, 1958), and that thus a larger amount of encoding resources may be devoted to processing distinctive events than are devoted to processing common events. Encoding tasks requiring greater resources may lead to better memory than do tasks requiring fewer resources (Tyler, Hertel, McCallum, \& Ellis, 1979).

All three encoding hypotheses have a common set of shortcomings as complete explanations of the effects of distinctiveness. First, a direct prediction of most encoding hypotheses is that rate of presentation should have an impact on the effects of distinctiveness. With relatively fast rates of presentation there is a high demand on the resources available for encoding. When encoding resources are scarce, increased resources devoted to distinctive items should be at the expense of processing surrounding items. This means that as rate of presentation increases, either the enhanced memory for distinctive items should decrease, or the negative effects of distinctiveness on the memory for surrounding items should increase. Interactions between rate of presentation and distinctiveness have been reported in a few studies (N. R. Ellis et al., 1971; Tulving, 1969). Many types of distinctiveness, however, appear to affect memory for distinctive and surrounding items independently of both the rate of presentation (Light et al., 1979; McDaniel \& Einstein, 1986; Schmidt, 1985) and whether presentation is experimenter- or subject-paced (Hunt \& Elliot, 1980; McDaniel \& Einstein, 1986).

A second problem with the encoding theories is the effect of type of test. With several definitions of distinctiveness (e.g., bizarre imagery), positive effects are found on free recall tests but not on cued recall and recognition tests (McDaniel \& Einstein, 1986). With other definitions (e.g., the concreteness effect), these effects of type of test were reversed, with the effects occurring in cued recall but not in free recall (Marshark \& Hunt, 1989). In addition, the negative effects of distinctiveness on the memory for background items may occur in recall but not in recognition (Schmidt, 1985). These effects of type of test are 
difficult to explain in terms of general increases in rehearsal, depth of processing, or attention.

A third problem with these theories concerns the effects of distinctiveness on the organization of recall. Distinctive items are recalled earlier than the same items in a homogeneous list (Schmidt, 1985) and tend to be recalled as a group (Bruce \& Gaines, 1976; Schmidt, 1985). It is unclear how pure encoding theories can explain these effects of distinctiveness on recall organization.

In summary, pure encoding explanations of distinctiveness fail to explain the effects of rate of presentation, the influence of type of memory test, and the effects of distinctiveness on organization in recall. In addition, Mitchell and Hunt (1989) have argued that variation in the allocation of encoding resources is an inadequate explanation of variation in memory.

\section{Retrieval Explanations}

An alternative approach to explaining the effects of distinctiveness is to focus on processes occurring during retrieval. Rather than quantitative differences in memory resulting from different "amounts" of processing, there may be qualitative differences between the stored representations of distinctive and common events (Bird, 1980). If the distinctive features of an item are stored, the item may "stand out" from other information in memory. Von Restorff argued that "the trace of the isolated item becomes the 'figure' which stands out against the aggregated homogeneous traces, the "ground" '(Wallace, 1965, p. 418).

Several mechanisms may be responsible for a retrieval advantage enjoyed by distinctive memory traces. First, distinctive information may be retrieved first (Schmidt, 1985), leading to a greater probability of recalling distinctive information than of recalling common information by virtue of the greater output interference suffered by common items. Second, the distinctive information may be placed in a special mnemonic category, whereas the rest of the material is stored in a larger category of background items (Bruce \& Gaines, 1976). This organizational hypothesis provides an explanation of the effects of distinctiveness on clustering. Using the "cue-overload" hypothesis (Watkins \& Watkins, 1975), the probability of recalling items from the small category (i.e., distinctive items) is greater than the probability of recalling items from the large category (background items). In a homogeneous list, the items may all belong to one conceptual category, and thus recall of target items in the homogeneous list is lower than recall of the same items when they are distinctive.

However, output interference and cue overload are clearly inadequate as explanations of the effects of distinctiveness. These mechanisms apply only when mixedlist designs are employed to study the effects of distinctiveness. Thus, cue overload and output interference cannot explain emotional and processing distinctiveness. In addition, the effects of output interference and cue overload can be minimized on recognition tests. Nonetheless, when the order of testing common and distinctive items is counterbalanced, and when the number of common and distinctive items tested is equated, the effects of distinctiveness on recognition are still found across a variety of definitions of distinctiveness (e.g., Going \& Read, 1974; Hunt \& Elliot, 1980; Schmidt, 1985). Furthermore, Schmidt (1985) tested the cue-overload hypothesis directly by measuring subjective organization in the recall of homogeneous lists and lists containing conceptually distinctive items. In contradiction to the hypothesis, distinctive items were recalled in larger categories than common items were.

In summary, retrieval explanations for the effects of distinctiveness appear promising in that they explain the effects of distinctiveness on organization in recall. However, they fail to explain: (1) effects of distinctiveness in between-subjects designs, (2) the positive effects of distinctiveness found on recognition tests in within-subjects designs, and (3) why certain types of distinctiveness have negative effects on background-item recall whereas other types do not.

\section{Encoding and Retrieval Explanations}

Eysenck's model. Eysenck (1979) presented an encoding and retrieval explanation of distinctiveness. His theory was based on an analysis of sets of information encoded prior to the experiment, during the study trial, and during the memory test. The study-trial encoding was thought to include some information previously encoded plus some new information unique to the experimental session. On a recognition test, the encoding of an "old" item included information unique to the test trial, information exclusively from preexperimental encodings, information unique to the experimental encoding, and information shared by the experimental encoding and previous encodings. Performance on the recognition test was determined primarily by "the extent to which the test-trial encoding contains information that is unique to the studytrial encoding"' (p. 111).

The distinctiveness of an item depends not only on the relation between the various encodings of that item, but on the amount of overlap between the study-trial encoding of that item and the study-trial encodings of other items in a list (Eysenck, 1979, p. 94). The recognition process thus depends on information that is both unique to the study-trial encoding and unique to the target item. Eysenck added a second mechanism to help explain the effects of distinctiveness. He argued that "it is often the case that distinctive stimuli are well remembered because they are more thoroughly processed than nondistinctive stimuli" (p. 94), adding an encoding-resource component to his theory. The increased processing of an item has its effect by increasing the total amount of information stored during the study-trial encoding. This, in turn, will generally lead to the storage of a greater amount of information unique to the experimental setting, increasing the probability of recognition.

Eysenck's hypothesis has the potential to explain several of the classes of distinctiveness outlined above. The hypothesis was designed to explain the effects of depth of 
processing. Semantic orienting tasks were thought to lead to traces that shared fewer preexperimental encodings than did the traces resulting from nonsemantic orienting tasks. In primary distinctiveness, the distinctive items should have limited feature overlap with other study-trial encodings. In secondary distinctiveness, a distinctive item should share fewer features with preexperimental encodings than would a common item. In each case, limited feature overlap should aid discrimination of distinctive items from other information in memory.

In spite of its many strengths, Eysenck's (1979) hypothesis falls short of a comprehensive model of distinctiveness. Most problematic is Eysenck's focus on recognition performance. It is not clear how the hypothesis explains the effects of distinctiveness on free recall. A second problem is that a common framework was used in explanations of a variety of phenomena. However, this common mechanism cannot explain the varied effects of distinctiveness in which distinctiveness aids recall but not recognition, aids recognition but not recall, increases memory for detail, hurts memory for detail, suppresses recall for background material, does not suppress recall of background material, and so on, all depending on how distinctiveness is operationalized.

A third problem with Eysenck's model is that it incorrectly predicts that the effects of secondary distinctiveness should be larger in between- than in within-list designs. As the number of distinctive items in a list increases, the amount of feature overlap between list items should decrease, leading to increasing effects of distinctiveness. This follows from Rosch and Mervis's (1975) analysis of conceptual relations. Common items are similar to the prototype, and thus share a great number of features with the prototype and with other common category members. Distinctive category members are dissimilar to the prototype, and should generally be less similar to other distinctive items than to common items. Light et al. (1979) empirically demonstrated this point using ratings of similarity between pairs of faces. Pairs of common faces were rated as more similar than pairs of distinctive faces. Thus, an unadorned feature overlap model of distinctiveness predicts that the magnitude of the effects of secondary distinctiveness will be larger in between-list comparisons, in which many distinctive items share few features, than in within-list comparisons, in which distinctive items share some features with common items. This prediction is contradicted by the influence of list structure on the effects of secondary distinctiveness such as orthographic distinctiveness and bizarre imagery.

Hunt's distinctiveness hypothesis. Perhaps the most compelling theory of distinctiveness has been developed by Hunt and his associates (Hunt \& Einstein, 1981; Hunt \& Elliot, 1980; Hunt \& Mitchell, 1978, 1982; Marschark \& Hunt, 1989). This explanation of distinctiveness relies heavily on the distinction between individual-item and relational information. Individual-item information serves to distinguish between items in a set, whereas relational information defines the relations within the set and delineates one memory set from another. During retrieval, relational information can be used to define a search set, whereas individual-item information defines to-be-remembered targets in the set. Distinctive items contain individual-item information that facilitates discriminations between items in a search set. In addition, distinctive items may be processed as a group and thus encourage relational processing between members in the group. Any number of dimensions may produce individual and relational information, including perceptual, conceptual, or imaginal processes.

Hunt's distinctiveness hypothesis provides a fair account of a number of different types of distinctiveness, including orthographic distinctiveness (Hunt \& Einstein, 1981) and category distinctiveness (Hunt \& Mitchell, 1982). Similar frameworks have been adopted to explain bizarre imagery (McDaniel \& Einstein, 1986), the concreteness effect (Marschark \& Hunt, 1989), and the generation effect (Schmidt \& Cherry, 1989). Furthermore, the hypothesis does not seem at odds with Eysenck's (1979) ideas. Perhaps Eysenck's hypothesis could be employed as a model of individual-item information, in which feature overlap defines the extent to which the individual-item information available at retrieval is useful for discriminations.

Nonetheless, the hypothesized effects of distinctiveness on individual-item and relational processing fail to provide a comprehensive theory of distinctiveness. Distinctive individual-item information concerning emotional events does not explain the paradoxical effects of trauma reported by Loftus and Burns (1982) and Christianson and Loftus (1987). It is unclear why, according to this theory, the effects of secondary distinctiveness occur mainly in mixed-list or within-subjects designs. Hunt and Elliot (1980) argued that the subjects only "perceived" the manipulation of orthographic distinctiveness in mixed-list designs, so that the effects of orthographic distinctiveness on memory are only obtained in these types of designs. However, this argument seems to contradict the Hunt and Mitchell (1982) claim that orthographic distinctiveness is coded automatically.

Hunt's hypothesis also has difficulty explaining interactions between distinctiveness and type of memory test. Marshark and Hunt (1989) argued that the search set is not clearly delineated in free recall, and that thus variation in individual-item information within the search set is of little value. Thus the effects of distinctiveness are generally more pronounced in recognition or cued recall, in which the search set is clearly defined, than they are in free recall. Hunt and Mitchell (1982) argued that distinctive items can be processed as a group, leading to clustering in recall, and presumably to greater effects of distinctiveness in recall than in recognition. In reality, some types of distinctiveness influence recall but not recognition (e.g., bizarre imagery, physical distinctiveness), other types of distinctiveness enhance recognition but suppress recall (e.g., word frequency in between-list designs), and some types of distinctiveness appear to enhance memory as measured by both types of tests (depth 
of processing, category distinctiveness, high-priority items, orthographic distinctiveness, etc.).

Finally, Hunt's hypothesis does not provide a compelling explanation as to why distinctive information in a mixed list sometimes suppresses memory for the common information in the list, sometimes has no effect on the memory of the common information, and sometimes suppresses recall of the common information but not recognition of that information. A partial explanation for these varied effects was offered by Hunt and Mitchell (1982). They argued that distinctive individual-item information may be encoded as a result of automatic processes, and that thus distinctiveness does not necessarily lead to suppression of background-item recall and recognition. Thus, physical and orthographic distinctiveness have positive effects on recall without having negative effects on memory for background items. In addition, some types of distinctiveness (e.g., category distinctiveness) lead to increases in relational processing at the expense of the relational processing of the background items, leading in turn to a negative effect on the recall of background items. There are two major problems with this explanation. First, this hypothesis does not explain negative effects of distinctiveness on the recognition of background items $(N$. R. Ellis et al., 1971; Schulz, 1971). Second, Schmidt (1985) demonstrated that background items receive more, not less, relational processing in lists containing distinctive information than in homogeneous lists.

\section{The Incongruity Hypothesis}

A comprehensive theory of distinctiveness, encompassing the many definitions of distinctiveness and their varied effects on memory, cannot be offered. In its place, a more restrictive definition of distinctiveness should be used to guide theoretical development. According to this definition, distinctive events are those that are incongruent with active conceptual frameworks, or that contain salient features not present in active memory. These events lead to increased attention in direct proportion to the degree of incongruity. Increased attention is associated with the orienting response and with cortical arousal. However, as noted earlier, these physiological measures cannot be used as independent indices of incongruity. Incongruity must be determined by collecting ratings of conceptual relations within a specific context by a specific subject group.

This limited definition of distinctiveness removes from consideration two classes of phenomena that have been previously attributed to distinctiveness. Emotional stimuli, by their very nature, lead to both physiological and psychological processes too complex and varied to be explained solely in terms of incongruity. Definitions of distinctiveness tied to processes rather than to conceptual relations are also outside of the bounds of this theory. Some of the same physiological and psychological processes involved in enhanced memory resulting from depth of processing manipulations may also be involved in enhanced memory for incongruous events. Nonetheless, we can conceptually separate processing-based and incongruity-based manipulations, and these classes of manipulations have different effects on memory performance.

The incongruity hypothesis represents an integration of recent theoretical developments concerning conceptual relations (Murphy \& Medin, 1985), Hunt's distinctiveness hypothesis, and information processing approaches to the orienting response (e.g., Ohman, 1979). According to this hypothesis, incongruity affects memory performance during three phases of processing. During presentation, a stimulus is compared with active conceptual frameworks. An attentional response is evoked in inverse proportion to the degree of overlap between the stimulus and the active information (Phase 1). However, incongruity is necessarily context-bound (Murphy \& Medin, 1985; Nosofsky, 1986). For example, in a list of conceptually related words, subjects may place a great deal of weight on the fact that the words are all members of the same conceptual category. But in the context of many stimuli that have little in common, a person may focus on what the stimuli do have in common. Thus, in a list of orthographically distinctive words, in which few features are shared between words, subjects may attach great weight to the fact that all the stimuli are English words, and little weight to the fact that the words contain different orthographic features. A simple mechanism may account for such changes in feature weights. In the absence of specific strategies that highlight certain features (e.g., Pendergrass \& Kimmel, 1968), the weight given to a particular feature may be a direct function of the number of times that that feature has been recently processed.

Increased attentiveness to distinctive stimuli occurs during the first second or so of processing (Karis et al., 1984); it is automatic (Ohman, 1979); and it results in increased storage of individual-item information (Eysenck, 1979). In addition, an incongruent event separates experience into three groups of phenomena: events occurring prior to incongruity, information related to the incongruent event, and events occurring after the incongruent event. Following these initial responses, numerous controlled processes are carried out, including elaboration, relational processing, and rehearsal (Phase 2). The effects of these controlled processes may serve to facilitate or to inhibit the effects of incongruity, depending on the structure of the to-be-remembered material, individual strategies employed by the subject, and the nature of the memory test. Later, during the memory test (Phase 3), the effects of incongruity on memory will depend on the degree to which stored information supports good memory performance (as described by Desrochers \& Begg, 1987). As a result of the complex interactions between Phases 1, 2, and 3, increased attention is not a sufficient cause of enhanced memory for incongruent events.

Some specific support for the framework above was reported by Karis et al. (1984), who investigated individual differences in the effects of distinctiveness on cortical responses and memory. Evoked potentials indicative of increased attention to physically distinctive items were 
observed in each of the subjects tested. However, not all subjects demonstrated a von Restorff effect. An analysis of individual strategies indicated that some subjects employed organization and rehearsal patterns that diminished the effects of distinctiveness. Karis et al. argued that these results were consistent with a two-phase model of information processing. Phase 1 occurs during the first second of processing, involves encoding and categorization, and is related to the $P 300$ response. Phase 2 operates during the memory test and is subject to individual retrieval strategies. The current framework adds a third phase. During presentation, a subject may also employ mnemonic strategies that will affect the outcome of manipulations of distinctiveness.

The incongruity hypothesis provides a straightforward explanation of the effects of primary distinctiveness reviewed above. The effects of distinctiveness should vary as the degree of incongruity increases. Thus, physical distinctiveness leads to small effects on recall and to unreliable effects on recognition. The effects of primary distinctiveness are more pronounced in recall than in recognition because the distinctive items share physical or conceptual features, thereby leading to relational processing (Phase 2) and clustering in recall (Phase 3) (Bruce \& Gaines, 1976; Schmidt, 1985). Stronger attentional responses are evoked with category distinctiveness and priority manipulations than are evoked with physical distinctiveness, leading to enhanced recall and recognition.

The effects of secondary distinctiveness can be explained as follows. Distinctive items, such as unusual faces and orthographically distinctive words, are atypical members of their conceptual classes. In the context of typical members of its conceptual class, the distinctive item will be incongruous, leading to increased attention and storage of individual-item information. For example, features shared by words of common orthography will be active following presentation of several common words. Orthographically distinctive words will contain different features, leading to increased attention and increased storage of individual-item information. In the context of many distinctive items, a different set of features becomes prominent in active memory. For example, in the context of a list of orthographically distinctive words, orthographic features receive little weight (because few orthographic features are shared between items), and any features shared between the words will remain active in memory. The presentation of a nonword may lead to incongruity, but the presentation of yet another unusual word should lead to little response. Thus, the effects of orthographic distinctiveness and other types of secondary distinctiveness depend on recent presentation of typical category members.

According to the framework above, manipulations of secondary distinctiveness should not lead to clustering of distinctive items. When items are distinctive because they are atypical members of a category, these items do not share a set of features, and thus there is no means to organize recall. This is in contrast to the effects of primary distinctiveness, in which distinctive items may also share features. Thus, primary distinctiveness leads to clustering in recall (see, e.g., Schmidt, 1985), whereas secondary distinctiveness does not (see, e.g., Einstein \& McDaniel, 1987; Hunt \& Mitchell, 1982).

Explaining the effects of secondary distinctiveness on memory for sentences (see, e.g., McDaniel \& Einstein, 1986) and word pairs (see, e.g., Hirshman, 1988) is more difficult. Because within-subjects designs are necessary to produce these effects, feature comparisons must take place across sentences and word pairs. A common sentence must share more features with a common sentence than it shares with a bizarre sentence. Thus, in the context of common sentences, a bizarre sentence leads to incongruity and to increased storage of sentence information.

One of the puzzles that remains concerning the effects of secondary distinctiveness is why some types of secondary distinctiveness enhance recall and recognition, whereas other types of secondary distinctiveness only enhance recall. A partial resolution to the inconsistent effects of secondary distinctiveness can be found if one distinguishes between intra- and interitem incongruity. In both bizarre imagery and the expectation-violation effect, incongruity arises within the to-be-remembered item (i.e., intraitem), and the effects are confined to free recall. This is in contrast to manipulations in which an integrated item (e.g., a face) is an atypical member of a conceptual class (i.e., interitem incongruity). Interitem incongruity leads to enhanced recall and recognition. Perhaps item integration important for Phases 2 and 3 is disrupted by intraitem incongruity.

As noted above, there is little evidence that distinctive items somehow "steal" attention from surrounding common items. Such an effect would be most evident on recognition tests in which items immediately surrounding distinctive items are tested, and in which the effects of relational processing on memory performance are minimized. Only two types of distinctiveness have demonstrated suppressed recognition of surrounding items. N. R. Ellis et al. (1971) reported suppression of material surrounding a nude picture, a manipulation associated with sexual arousal. Tulving (1969) reported suppression of material surrounding high-priority items, a manipulation that confounded physical distinctiveness, conceptual distinctiveness, significance, and retrieval order. In both cases, mechanisms other than those associated with incongruity may have been responsible for the suppressed recognition of surrounding items. In terms of the current framework, incongruity leads to an increase in attentional resources (see, e.g., Kahneman, 1973) and thus does not lead to a decrease in the attention given to surrounding material. Suppressed recall of common items due to the presence of distinctive items is the result of organizational and retrieval processes operating during Phases 2 and 3 outlined above. Thus suppression effects are not necessarily focused on items immediately surrounding the distinctive items (Schmidt, 1985). Because the increased attention given to distinctive items occurs quickly and automatically, rate of presentation has little impact on the effects of distinctiveness. ${ }^{3}$ 
The incongruity hypothesis developed above leads to several novel predictions. First, it should not be possible to reverse the effects of secondary distinctiveness by varying list structure. Thus, even in a list that consists of $99 \%$ distinctive items and $1 \%$ common items, the common items will not be remembered better. In such a list, the distinctive items do not contain a set of shared features, and so a common item would overlap with features in active memory to the same extent as a distinctive item would. Several researchers have reported this predicted pattern of results (Hirshman et al., 1989; Schmidt, 1991).

A second prediction concerns the effects of spacing items during presentation. Because incongruity results from matching processes in active memory, manipulations that affect the content of working memory will have an impact on the effects of distinctiveness. For example, if a lengthy distractor activity separates items, active memory will only contain the features of the distractor task itself, and any verbal material (common or distinctive) may lead to incongruity. Under such conditions, the effects of distinctiveness should be eliminated. Some support for this prediction can be found in research concerning the build-up of proactive interference in short-term memory tasks. Proactive interference (and thus release from PI) does not occur if trials are separated by $2 \mathrm{~min}$ or more (Loess \& Waugh, 1967).

\section{CONCLUSIONS}

It has been more than 25 years since Wallace's (1965) review of the von Restorff effect. In that time, the concept of distinctiveness has been operationalized in many different ways. The many new faces of distinctiveness do not share a common definition, and the manipulations have led to a dismaying variety of results. An analysis of the theoretical alternatives revealed that the many types of distinctiveness could not be accounted for by a single theoretical framework. In the absence of a cogent definition, a common pattern of results, or a compelling theory, it is inappropriate to explain any phenomenon in memory research by invoking the concept of "distinctiveness," or by labeling the phenomena a "von Restorff effect." Invoking the label "distinctiveness" provides little more than a vague reference to a diverse literature and the illusion of understanding.

A potential criticism of the arguments presented above is that, although distinctiveness on its own cannot explain all the varied results presented above, perhaps distinctiveness in concert with other mechanisms can explain these phenomena. In other words, distinctiveness may be an important part of a more complex, as yet unstated, theory of memory. For this criticism to be valid, "distinctiveness" must be defined independently of measures of memory. In addition, this new definition of distinctiveness must be applicable to the broad range of phenomena reviewed above. Only then could one attempt to construct a unifying theory. Given the conceptual difficulties surrounding the definition of distinctiveness, and the bewildering array of empirical findings, it seems best to re- main skeptical that a unifying theory of distinctiveness can be offered.

As an answer to the conceptual difficulties surrounding "distinctiveness," the search for a unifying theory should be abandoned. In its place, the incongruity hypothesis has been proposed. Incongruent events are clearly defined in this framework as events that do not fit an active cognitive structure, leading to increased attention and storage of individual-item information. Ratings of similarity, confined to a specific context, provide an independent means of measuring conceptual congruity. This definition should help avoid the circularity found in previous definitions of distinctiveness. In primary distinctiveness, incongruity results from a mismatch of features from an item with features in primary memory from other recently presented items. In secondary distinctiveness, incongruity is defined with respect to typical category members stored in secondary memory. However, because increased attention is a result of mismatches in active memory, a representation of typical category members must be present in active memory for secondary distinctiveness to influence memory performance. Increased attention is only Phase 1 of a three-phase process. Depending on the definition of distinctiveness, distinctive items may also be processed as a group, or receive special status during retrieval.

We can have a theory of memory based on distinctiveness, as long as that theory is limited to explaining a group of phenomena that share an operational definition and lead to consistent effects on memory. Primary and secondary distinctiveness represent such a group of phenomena, and the incongruity hypothesis provides a reasonable account of the effects of primary and secondary distinctiveness on memory.

\section{REFERENCES}

Anderson, J R., \& Bower, G. H. (1972). Recognition and retrieval processes in free recall. Psychological Review, 79, 97-123.

Atkinson, R. C. \& Shiffrin, R. M. (1968). Human memory: A proposed system and its control processes. In K. W. Spence \& J. T. Spence (Eds.), The psychology of learning and motivation: Advances in research and theory (Vol. 2, pp. 89-195). New York: Academic Press.

BADDELY, A. D. (1978). The trouble with levels: A reexamination of Craik and Lockhart's framework for memory research. Psychological Review, 85, 139-152.

BEGG, I., SNIDER, A. (1987) The generation effect: Evidence for generalized inhibition. Journal of Experimental Psychology: Learning, Memory, \& Cognition, 13, 553-563.

BeGG, I., Snider, A., Foley, F., \& Goddard, R. (1989). The generation effect is no artifact: Generating makes words distinctive. Jour nal of Experimental Psychology: Leaming, Memory, \& Cognition, 15, 977-989.

BirD, C. P. (1980). The isolation effect as a function of unique processing orientation. Journal of Experimental Psychology: Human Learning \& Memory, 6, 267-275.

Bohannon, J. N. (1988). Flashbulb memories of the space shuttle disaster: A tale of two theories. Cognition, 29, 179-196.

Bower, G. H. (1981). Mood and memory. American Psychologist, 36, 129-148.

Bower, G. H. , Black, J. B , \& Turner, T J. (1979). Scripts in memory for text. Cognitive Psychology, 11, 177-220.

Brown, R , \& Kulik, J (1977). Flashbulb memories. Cognition, 5 73-99 
Bruce, D., \& Gaines, M. T. (1976). Tests of an organizational hypothesis of isolation effects in free recall. Journal of Verbal Learning \& Verbal Behavior, 15, 59-72.

Cermak, L. S., \& CraIK, F. I. M. (1979). Levels of processing in human memory. Hillsdale, NJ: Erlbaum.

Christianson, S.-A. (1989). Flashbulb memories: Special, but not so special. Memory \& Cognition, 17, 435-443.

Christianson, S.-Ä, Loftus, E. F. (1987). Memory for traumatic events. Applied Cognitive Psychology, 1, 225-239.

Clark, M., Milberg, S., \& Ross, J. (1983). Arousal cues arousalrelated material in memory: Implications for understanding effects of mood on memory. Journal of Verbal Leaming \& Verbal Behavior, 22, 633-649.

Clifford, B. R., \& Hollin, C. R. (1981). Effects of the type of incident and the number of perpetrators on eyewitness memory. Journal of Applied Psychology, 66, 364-370.

CohEN, M. E., \& CARR, W. J. (1975). Facial recognition and the von Restorff effect. Bulletin of the Psychonomic Society, 6, 383-384.

Conway, M. A., \& Gathercole, S. E. (1987). Modality and longterm memory. Journal of Memory \& Language, 26, 341-361.

Conway, M. A., \& Gathercole, S. E. (1990). Writing and long-term memory: Evidence for a "translation" hypothesis. Quarterly Journal of Experimental Psychology, 42A, 513-527.

Cronbach, L. J., Meehl, P. E. (1955). Construct validity in psychological tests. Psychological Bulletin, 52, 281-302.

Craik, F. I. M., \& Blankstein, K. R. (1975). Psychophysiology and human memory. In P. H. Venables \& M. J. Christie (Eds.), Research in psychophysiology (pp. 388-417). London: Wiley.

Craik, F. I. M., LockharT, R. S. (1972). Levels of processing: A framework for memory research. Journal of Verbal Learning \& Verbal Behavior, 11, 671-684.

Craik, F. I. M., \& Tulving, E. (1975). Depth of processing and the retention of words in episodic memory. Journal of Experimental Psychology: General, 104, 268-294.

Desrochers, A., \& BeGG, I. (1987). A theoretical account of encoding and retrieval processes in the use of imagery-based mnemonic techniques: The special case of the keyword method. In M. A. McDaniel \& M. Pressley (Eds.), Imagery and related mnemonic processes: Theories, individual differences, and applications (pp. 56-77). New York: Springer-Verlag.

DunCAN, C. P. (1974). Retrieval of low-frequency words from mixed lists. Bulletin of the Psychonomic Society, 4, 137-138.

Einstein, G. O., \& MCDANiel, M. A. (1987). Distinctiveness and the mnemonic benefits of bizarre imagery. In M. A. McDaniel \& M. Pressley (Eds.), Imagery and related mnemonic processes: Theories, individual differences, and applications (pp. 78-102). New York: Springer-Verlag.

Einstein, G. O., McDaniel, M. A., \& Lackey, S. (1989). Bizarre imagery, interference, and distinctiveness. Journal of Experimental Psychology: Learning, Memory, \& Cognition, 15, 137-146.

ELLIS, H. C. (1985). On the importance of mood intensity and encoding demands in memory: Commentary on Hasher, Rose, Zacks, Sanft, and Doren. Journal of Experimental Psychology: General, 114, 392-395.

Ellis, H. C., Thomas, R. L., McFarland, A. D., \& Lane, J. W. (1985). Emotional mood states and retrieval in episodic memory. Journal of Experimental Psychology: Learning, Memory, \& Cognition, 11, 363-370.

Ellis, H. C., Thomas, R. L., \& Rodriguez, I. A. (1984). Emotional mood states and memory: Elaborative encoding, semantic processing, and cognitive effort. Joumal of Experimental Psychology: Leaming, Memory, \& Cognition, 10, 470-482.

Ellis, N. R., Detrerman, D. K., Runcie, D., McCarver, R. B., \& Craig, E. (1971). Amnesic effects in short-term memory. Journal of Experimental Psychology, 89, 357-361.

EYSENCK, M. W. (1978). Levels of processing: A critique. British Journal of Psychology, 69, 157-169.

EYSENCK, M. W. (1979). Depth, elaboration, and distinctiveness. In L. S. Cermak \& F. I. M. Craik (Eds.), Levels of processing in human memory (pp. 89-118). Hillsdale, NJ: Erlbaum.

Friedman, A. (1979). Framing pictures: The role of knowledge in au- tomatized encoding and memory for gist. Journal of Experimental Psychology: General, 108, 316-355.

GARDINER, J. M., GREGG, V. H. (1979). When auditory memory is not overwritten. Journal of Verbal Learning \& Verbal Behavior, 18, 705-719.

GARNER, W. R., HAKe, H., \& ERIKSEN, C. W. (1956). Operationism and the concept of perception. Psychological Review, 63, 149-159.

Gathercole, S. E., \& ConWay, M. A. (1988). Exploring long-term modality effects: Vocalization leads to best retention. Memory \& Cognition, 16, 110-119.

GATI, I., \& BEN-ShaKhar, G. (1990). Novelty and significance in orientation and habituation: A feature-matching approach. Journal of Experimental Psychology: General, 119, 251-263.

GATI, I., \& TVERSKY, A. (1984). Weighting common and distinctive features in perceptual and conceptual judgments. Cognitive Psychology, 16, 341-370.

GATI, I., TVERSKY, A. (1987). Recall of common and distinctive features of verbal and pictorial stimuli. Memory \& Cognition, 15, 97-100.

GoING, M., \& READ, J. D. (1974). Effects of uniqueness, sex of subject, and sex of photograph on facial recognition. Perceptual \& Motor Skills, 39, 109-110.

Goodman, G. S. (1980). Picture memory: How the action schema affects retention. Cognitive Psychology, 12, 473-495.

Graesser, A. C., Gordon, S. E., \& SAWYer, J. D. (1979). Recognition memory for typical and atypical actions in scripted activities: Tests of a script pointer + tag hypothesis. Joumal of Verbal Learning \& Verbal Behavior, 18, 319-332.

Graf, P., \& RyN, L. (1990). Transfer-appropriate processing for implicit and explicit memory. Journal of Experimental Psychology: Learning, Memory, \& Cognition, 16, 978-992.

GreEN, R. T. (1958). The attention-getting value of structural change. British Journal of Psychology, 49, 311-314.

GREGG, V. H. (1976). Word frequency, recognition and recall. In J. Brown (Ed.), Recall and recognition (pp. 183-215). London: Wiley.

Gregg, V. H., Montgomery, D. C., \& Castano, D. (1980). Recall of common and uncommon words form pure and mixed lists. Journal of Verbal Learning \& Verbal Behavior, 19, 240-245.

Heuer, F., \& REISBERG, D. (1990). Vivid memories of emotional events: The accuracy of remembered minutiae. Memory \& Cognition, 18, 496-506.

HiRshman, E. (1988). The expectation-violation effect: Paradoxical effects of semantic relatedness. Journal of Memory \& Language, 27, 40-58.

Hirshman, E., \& BJoRK, R. A. (1988). The generation effect: Support for a two-factor theory. Journal of Experimental Psychology: Learning, Memory, \& Cognition, 14, 484-494.

Hirshman, E., Whelley, M. M., \& PaliJ, M. (1989). An investigation of paradoxical memory effects. Journal of Memory \& Language, 28, 594-609.

Hock, H. S., Romanski, L., Galie, A., \& Williams, C. S. (1978). Real-world schemata and scene recognition in adults and children. Memory \& Cognition, 6, 423-431.

Hunt, R. R., Einstein, G. O. (1981). Relational and item-specific information in memory. Journal of Verbal Learning \& Verbal Behavior, 20, 497-514.

Hunt, R. R., \& ELLIOT, J. M. (1980). The role of nonsemantic information in memory: Orthographic distinctiveness effects on retention. Journal of Experimental Psychology: General, 109, 49-74.

Hunt, R. R., \& Mitchell, D. B. (1978). Specificity in nonsemantic orienting tasks and distinctive memory traces. Joumal of Experimental Psychology: Human Learning \& Memory, 4, 121-135.

HunT, R. R., \& MitcheLL, D. B. (1982). Independent effects of semantic and nonsemantic distinctiveness. Journal of Experimental Psychology: Human Learning \& Memory, 8, 81-87.

IsEN, A. M. (1984). Toward understanding the role of affect in cognition. In R. Wyer \& T. Srull (Eds.), Handbook of social cognition (pp. 179-236). Hillsdale, NJ: Erlbaum.

IsEN, A. M. (1985). Asymmetry of happiness and sadness in effects on memory in normal college students: Comment on Hasher, Rods, Zacks, Sanft, and Doren. Journal of Experimental Psychology: General, 114, 388-391. 
JAMEs, W. (1950). The principles of psychology. New York: Dover (Original work published 1890)

Jenkins, W. O., Postman, L. (1948). Isolation and spread of effect in serial learning. American Journal of Psychology, 61, 214-221.

Johnston, C. D., \& Jenkins, J. J. (1971). Two more incidental tasks that differentially affect associative clustering in recall. Journal of $E x$ perimental Psychology, 89, 92-95.

Kahneman, D. (1973). Attention and effort. Englewood Cliffs, NJ Prentice-Hall.

KaPLAN, R. M., \& Pascoe, G. C. (1977). Humorous lectures and humorous examples: Some effects upon comprehension and retention. Journal of Educational Psychology, 69, 61-65.

Karis, D., Fabiani, M., \&onchin, E. (1984). "P300" and memory. Individual differences in the von Restorff effect. Cognitive Psychology, 16, 177-216.

KAUSLER, D. H. (1973). Orthographic distinctiveness of homonyms and the feature tagging hypothesis. American Journal of Psychology, 86, 141-149.

KeEnan, J. M., Baillet, S. D., Browin, P. (1984). The effects of causal cohesion on comprehension and memory. Joumal of Verbal Learning \& Verbal Behavior, 23, 115-126.

KinoshitA, S. (1989). Generation enhances semantic processing? The role of distinctiveness in the generation effect. Memory \& Cognition, 17, 563-571.

KINTSCH, W., \& BATES, E. (1977). Recognition memory for statements from a classroom lecture. Journal of Experimental Psychology: $\mathrm{Hu}$ man Learning \& Memory, 3, 150-159.

KLEINSMITH, L. J., \& KAPLAN, S. (1963). Paired-associate learning as a function of arousal and interpolated activity. Journal of Experimental Psychology, 65, 190-193.

Kolers, P. A. (1973). Remembering operations. Memory \& Cognition, 1, 347-355.

Kolers, P. A. (1974). Two kinds of recognition. Canadian Journal of Psychology, 28, 51-61.

Kolers, P. A. (1975). Memorial consequences of automatized encoding. Joumal of Experimental Psychology: Human Leaming \& Memory, 1, 689-701.

Kolers, P. A., \& Ostry, D. J. (1974). Time course of loss of information regarding pattern analyzing operations. Journal of Verbal Learning \& Verbal Behavior, 13, 599-612.

Light, L. L., Kayra-Stuart, F., Hollander, S. (1979). Recognition memory for typical and unusual faces. Joumal of Experimental Psychology: Human Learning \& Memory, 5, 212-228

LoEss, H., \& WAUGH, N. C. (1967). Short-term memory and intertrial interval. Journal of Verbal Learning \& Verbal Behavior, 6, 455-460.

LoFTus, E. F., \& BURNS, T. E. (1982). Mental shock can produce retrograde amnesia. Memory \& Cognition, 10, 318-323.

Maltzman, I., KANTOR, W., LANGdon, B. (1966). Immediate and delayed retention, arousal, and the orienting and defensive reflexes. Psychonomic Science, 6, 445-446.

Marschark, M. (1985). Imagery and organization in the recall of prose Journal of Memory \& Language, 24, 734-745.

MarscharK, M., \& Hunt, R. R. (1989). A reexamination of the role of imagery in learning and memory. Joumal of Experimental Psychology: Learning, Memory, \& Cognition, 15, 710-720

Marschark, M., Richman, C. L., Yuille, J. C., \& Hunt, R. R (1987). The role of imagery in memory: On shared and distinctive information. Psychological Bulletin, 102, 28-41.

MAY, R. B., \&RYK, H. E. (1970). Word sequence, word frequency, and free recall. Canadian Journal of Psychology, 24, 299-304.

McCloskey, M., Wible, C., CoHEN, N. (1988). Is there a special flashbulb memory mechanism? Journal of Experimental Psychology. General, 117, 171-181

McDaniel, M. A., Einstein, G. O. (1986). Bizarre imagery as an effective memory: The importance of distinctiveness. Journal of $E x$ perimental Psychology: Learning, Memory, \& Cognition, 12, 54-65

MCDaniel, M. A., WAdDill, P. J., EInstein, G. O. (1988). A contextual account of the generation effect: A three-factor theory. Journal of Memory \& Language, 27, 521-536.

MCGHEE, P. E. (1983). The role of arousal and hemisphenc lateralization in humor. In P. E. McGhee \& J. H. Goldstein (Eds ), Hand- book of humor research. Vol. 1. Basic issues (pp. 13-37). New York Springer-Verlag.

McLaughlin, J P (1968). Recall and recognition measures of the von Restorff effect in serial learning. Joumal of Experimental Psychology, 78, 99-102.

Mitchell, D. B , \& HUN , R. R (1989). How much "effort" should be devoted to memory? Memory \& Cognition, 17, 337-348

Morris, C. D , Bransford, J D , \& Franks, J. J. (1977). Levels of processing versus transfer appropriate processing. Journal of Verbal Leaming \& Verbal Behavior, 16, 519-533.

Murphy, G. L, Medin, D L. (1985) The role of theories in conceptual coherence. Psychological Review, 92, 289-316

Myers, J. L , Shinjo, M , Dufry, S. A. (1987). Degree of causal relatedness and memory. Joumal of Memory \& Language, 26, 453-465

NeISSER, U. (1982). Snapshots or benchmarks? In U. Neisser (Ed.), Memory observed (pp. 43-48). San Francisco: Freeman

NeLSON, D L. (1979). Rememberng pictures and words: Appearance, significance and name In L. S Cermak \& F. I. M. Craik (Eds.), Levels of processing in human memory (pp 45-76) Hillsdale, $\mathrm{NJ}$ : Erlbaum

Neville, H. J., Kutas, M., Chesney, G , Schmidt, A. L. (1986). Event-related brain potentials during initial encoding and recognition memory of congruous and incongruous words. Journal of Memory \& Language, 25, 75-92.

Nosofsky, R M. (1986) Attention, similarity, and the identificationcategorization relationship. Jourmal of Experimental Psychology: General, 115, 39-57.

O'Brien, E. J., MYers, J L. (1985). When comprehension difficulty improves memory for text. Journal of Experimental Psychology: Leaming, Memory, \& Cognition, 11, 12-21.

OHMAN, A. (1979). The orienting response, attention, and learning: An information-processing perspective. In H. D. Kimmell, E. H. van Olst, \& J E Orlebeke (Eds.), The orienting reflex in humans (pp. 443471). Hillsdale, NJ· Erlbaum

PaIvio, A. (1971). Imagery and verbal processes. New York: Holt, Rinehart \& Winston.

Paivio, A., Csapo, K. (1969) Concrete-image and verbal memory codes. Joumal of Experimental Psychology, 80, 279-285.

Pendergrass, B. E., Kimmel, H. D. (1968). UCR diminution in temporal conditioning and habituation. Joumal of Experimental $P_{s y}$ chology, 77, 1-6

Pezdek, K., Whetstone, T., Reynolds, K., Askari, N., * DOUgherTy, T. (1989). Memory for real-world scenes: The role of consistency with schema expectation. Joumal of Experimental Psychology. Learning, Memory, \& Cognition, 15, 587-595.

Pillemer, D (1984) Flashbulb memories of the assassination attempt on President Reagan. Cognition, 16, 63-80.

Pillemer, D (1990). Clarifying the flashbulb memory concept: Comment on McCloskey, Wible, and Cohen (1988). Joumal of Experimental Psychology: General, 119, 92-96.

RANDSDELL, S. R., \& Fischler, I. (1989) Effects of concreteness and task context on recall of prose among bilingual and monolingual speakers. Journal of Memory \& Language, 28, 278-291.

RaYmond, J E., \& ARNELL, K. M. (1990, November). Factors producing a temporary "blink" in attention in an RSVP task. Paper presented at the meeting of the Psychonomic Society, New Orleans.

Ritov, I., GATI, I., * TVERSKY, A. (1990). Differential weighting of common and distinctive components. Jourmal of Experimental Psychology: General, 119, 30-41.

Rosch, E. H , (1973). Natural categories. Cognitive Psychology, 4, 328-350.

Rosch, E. H., Mervis, C. B. (1975). Fuzzy set theory and class inclusion relations in semantic categories. Journal of Verbal Learming \& Verbal Behavior, 22, 509-525.

Rosen, R C., Beck, J. G. (1988). Patterns of sexual arousal: Psychophysiological processes and clinical applications. New York Gilford.

Rundus, D (1971). Analysis of rehearsal processes in free recall. Journal of Experimental Psychology, 89, 63-77.

SchmidT, S. R (1985). Encoding and retrieval processes in the memory 
for conceptually distinctive events. Joumal of Experimental Psychology: Learning, Memory, \& Cognition, 11, 565-578.

SchmidT, S. R. (1988, May). Is the generation effect a type of distinctiveness? Paper presented at the meeting of the Midwestern Psychological Association, Chicago, IL.

Schmidt, S. R. (1990a, November). Memory for humorous sentences: A preliminary analysis. Paper presented at the meeting of the Psychonomic Society, New Orleans.

SchmidT, S. R. (1990b). A test of resource-allocation explanations of the generation effect. Bulletin of the Psychonomic Society, 28, 93-96.

SchmidT, S. R. (1991). Evaluating the distinctiveness interpretation of the generation effect. Quarterly Joumal of Experimental Psychology, 43A(4).

Schmid, S. R., \& Cherry, K. (1989). The negative generation effect: Delineation of a phenomenon. Memory \& Cognition, 17, 359-369.

SCHULZ, L. S. (1971). Effects of high-priority events on recall and recognition of other events. Journal of Verbal Learning \& Verbal Behavior, 10, 322-330.

Slamecka, N. J., \& Graf, P. (1978). The generation effect: Delineation of a phenomenon. Journal of Experimental Psychology: Human Learning \& Memory, 4, 592-604.

Slamecka, N. J., \& KatSaiti, L. T. (1987). The generation effects as an artifact of selective displaced rehearsal. Journal of Memory \& Language, 26, 589-607.

SokoLov, E. N. (1963). Perception and the conditioned reflex. New York: Macmillan.

STEIN, B. S. (1978). Depth of processing reexamined: The effects of precision of encoding and test appropriateness. Journal of Verbal Learning \& Verbal Behavior, 17, 165-174.

Tulving, E. (1969). Retrograde amnesia in free recall. Science, 164, 88-90.

TVERSKY, A. (1977). Features of similarity. Psychological Review, 84, 327-352.

Tyler, S. W., Hertel, P. T., McCallum, M. C., \& Ellis, H. C. (1979). Cognitive effort and memory. Joumal of Experimental Psychology: Human Leaming \& Memory, 5, 607-617.

Van Dam, G., Peeck, J., Brinkerink, M., \& Gorter, U. (1974). The isolation effect in free recall and recognition. American Journal of Psychology, 87, 497-504.

VON ReSTORFF, H. (1933). Über die Wirkung von Bereichsbildungen im Spurenfeld. Psychologische Forschung, 18, 299-342.

WALLACE, W. P. (1965). Review of the historical, empirical, and theoretical status of the von Restorff phenomenon. Psychological Bulletin, 63, 410-424.

WatKINS, O. C., \& Watkins, M. J. (1975). Buildup of proactive inhibition as a cue-overload effect. Journal of Experimental Psychology: Human Learning \& Memory, 104, 442-452.

WAUGH, N. C. (1969). Free recall of conspicuous items. Journal of Verbal Learning \& Verbal Behavior, 8, 448-456.

Weichselgartner, E., \& SperLing, G. (1987). Dynamics of automatic and controlled visual attention. Science, 238, 778-780.
Wollen, K. A., Weber, A., \& Lowry, D. H. (1972). Bizarteness versus interaction of mental images as determinants of learning. Cognitive Psychology, 3, 518-523.

ZECHMEISTER, E. B. (1969). Orthographic distinctiveness. Journal of Verbal Learning \& Verbal Behavior, 8, 754-761.

ZECHMEISTER, E. B. (1972). Orthographic distinctiveness as a variable in word recognition. American Journal of Psychology, 85, 425-430.

\section{NOTES}

1. I wish to thank Mark McDaniel for pointing out this pitfall in defining distinctiveness in terms of physiological responses.

2. Most within-subjects designs are also mixed-list designs as well, in which the distinctive and common material are embedded in a single list and presented to a single group of subjects. (For an exception, see Einstein, McDaniel, \& Lackey, 1989.) Mixed-list designs can lead to a problem in the interpretation of the effects of distinctiveness. If memory for distinctive items is compared to memory for the common items in the same list, positive effects on memory for the distinctive items cannot be distinguished from negative effects on memory for the common items. To avoid this problem, memory for items in mixed lists is usually compared to memory for the same items in homogeneous or unmixed lists. For example, McDaniel and Einstein (1986) compared memory for bizarre and common sentences in a mixed list to memory for sentences in lists containing only common or only bizarre sentences. Such comparisons can be made either within or between subjects, but most researchers have used separate groups of subjects for these baseline comparisons. In the discussion below, I will refer to designs in which the same subjects experience distinctive and common items in the same experimental session as within-subjects designs, even though a betweensubjects comparison group was employed. In what I will refer to as between-subjects designs, each subject experiences either common or distinctive information, but not both. Unfortunately, only a few researchers have systematically explored the effects of distinctiveness as a function of experimental design.

3. At very rapid rates of presentation (i.e., more than two items per second), distinctive items may rob attention from following items. For example, Weichselgartner and Sperling (1987) inserted a physically distinctive target item in a stream of items presented at 10 frames per second. Subjects were asked to report the target and the first four items that followed the target. Correct reports followed a bimodal distribution, with the first peak occurring concurrently with the target and the second peak occurring between 200 and $300 \mathrm{msec}$ after the target. Raymond and Arnell (1990) referred to the loss of items between the two peaks as an "attentional blink." Such an effect would go unnoticed at the relatively slow rates of presentation employed in most studies of long-term memory performance.

(Manuscript received July 16, 1990; revision accepted for publication May 14, 1991.) 